\title{
Analysis of rotorcraft wind turbine wake encounters using piloted simulation
}

\author{
Alexander Štrbac ${ }^{1} \cdot$ Tanja Martini $^{1} \cdot$ Daniel H. Greiwe ${ }^{1} \cdot$ Frauke Hoffmann $^{1} \cdot$ Michael Jones $^{1} \mathbb{C}$
}

Received: 19 November 2019 / Revised: 10 December 2020 / Accepted: 22 January 2021 / Published online: 9 March 2021

(c) The Author(s) 2021

\begin{abstract}
The use of offshore wind farms in Europe to provide a sustainable alternative energy source is now considered normal. Particularly in the North Sea, a large number of wind farms exist with a significant distance from the coast. This is becoming standard practice as larger areas are required to support operations. Efficient transport and monitoring of these wind farms can only be conducted using helicopters. As wind turbines continue to grow in size, there is a need to continuously update operational requirements for these helicopters, to ensure safe operations. This study assesses German regulations for flight corridors within offshore wind farms. A semi-empirical wind turbine wake model is used to generate velocity data for the research flight simulator AVES. The reference offshore wind turbine NREL $5 \mathrm{MW}$ has been used and scaled to represent wind turbine of different sizes. This paper reports result from a simulation study concerning vortex wake encounter during offshore operations. The results have been obtained through piloted simulation for a transport case through a wind farm. Both subjective and objective measures are used to assess the severity of vortex wake encounters.
\end{abstract}

Keywords Vortex-rotor interaction $\cdot$ Wake encounter $\cdot$ Wind turbine wake $\cdot$ Flight safety $\cdot$ Piloted simulation $\cdot$ Helicopter offshore operation

\section{List of symbols}

$c(0.93 R)$

$f$

$t_{\mathrm{EN}}$

$x, y, z$

$y_{0}$

$x_{\mathrm{WT}}, y_{\mathrm{WT}}, z_{\mathrm{WT}}$

$\Delta x_{\mathrm{WT}}, \Delta y_{\mathrm{WT}}, \Delta z_{\mathrm{WT}}$

$x_{\mathrm{EN}}, y_{\mathrm{EN}}, z_{\mathrm{EN}}$

$C_{\mathrm{T}, \mathrm{WT}}=\frac{T_{\mathrm{WT}}}{\frac{\rho}{2} V_{\mathrm{W}}^{2} A_{\mathrm{WT}}}$

$C_{\mathrm{T}}=\frac{T_{\mathrm{WT}}}{\rho U^{2} A_{\mathrm{WT}}}$

F

Alexander Štrbac

Alexander.Strbac@DLR.de

1 German Aerospace Center (DLR), Institute of Flight Systems, Lilienthalplatz 7, 38108 Braunschweig, Germany
M

Rotor blade chord, chord at $0.93 R, \mathrm{~m}$

Rotational frequency, $1 / \mathrm{min}$

Time of vortex encounter, $s$

Coordinates in the rotor hub frame, $\mathrm{m}$

Distance between the helicopter rotor

hub and the vortex core, $m$

Coordinates in the wind turbine

frame, $m$

Spatial discretization of the wind

lookup table, $\mathrm{m}$

Position of the vortex encounter in the

wind turbine frame, $\mathrm{m}$

Thrust coefficient, wind turbine

definition

Thrust coefficient, helicopter

definition

Blade element aerodynamic force, $\mathrm{N}$
$N_{\mathrm{b}}$

$P$

$R$

$R_{\mathrm{c}}, R_{\mathrm{c} 0}$

$R_{\mathrm{H}}$

$\tilde{R}^{\mathrm{H}}$

$U$

$V_{\mathrm{i}}$

$V_{\mathrm{c}}$

$V_{\mathrm{W}}$

$V_{\mathrm{W}, \Omega \min }, V_{\mathrm{W}, \Omega \max }$

$V_{\mathrm{W}, \mathrm{T}}, V_{\mathrm{W}, \mathrm{G}}, V_{\mathrm{W}, \mathrm{L}}$

$V_{\infty}$

$V_{x}, V_{y}, V_{z}$

\section{$\alpha$}

$\beta$

$\beta_{0}, \beta_{\mathrm{S}}, \beta_{\mathrm{C}}$
Blade element aerodynamic moment, $\mathrm{Nm}$

Rotor number of blades

Rotor power, MW

Wind turbine rotor radius, $\mathrm{m}$

Tip vortex core radius and its initial value, $m$

Helicopter main rotor radius, $\mathrm{m}$

Radial distance from vortex core, $\mathrm{m}$

Rotor blade tip speed, m/s

Induced velocity, $\mathrm{m} / \mathrm{s}$

Tip vortex peak velocity, $\mathrm{m} / \mathrm{s}$

Wind speed, $\mathrm{m} / \mathrm{s}$

Wind turbine cut-in and cut-out wind speed, $\mathrm{m} / \mathrm{s}$

Total, global and local wind speed, $\mathrm{m} / \mathrm{s}$

Helicopter flight speed, kts

North, east and down velocities of local wind speed, $\mathrm{m} / \mathrm{s}$

Angle of attack, ${ }^{\circ}$

Sideslip angle, ${ }^{\circ}$

Mean, lateral and longitudinal flap-

ping angles, ${ }^{\circ}$ 


$\begin{array}{ll}\delta_{\text {lat }}, \delta_{\text {lon }}, \delta_{\text {ped }}, \delta_{\text {col }} & \begin{array}{l}\text { Roll, pitch, yaw and collective com- } \\ \text { mand, } \%\end{array} \\ \theta_{0}, \theta_{\mathrm{S}}, \theta_{\mathrm{C}} & \begin{array}{l}\text { Collective, longitudinal and lateral } \\ \text { control angles, }\end{array} \\ \Psi_{\mathrm{B}} & \text { Rotor blade azimuth angle, }^{\circ} \\ \Gamma, \Gamma_{0} & \begin{array}{l}\text { Tip vortex circulation and its initial } \\ \text { value, } \mathrm{m} / \mathrm{s}^{2}\end{array} \\ \Phi, \Theta, \Psi & \text { Roll, pitch and yaw angles, } \\ \Omega & \text { Rotor rotational speed, } \mathrm{rad} / \mathrm{s}\end{array}$

\section{Introduction}

Europe's efforts to development of a sustainable and affordable energy production are leading to the rapid expansion of offshore wind energy. Since 2014, the average nominal power of newly installed offshore wind turbines has grown at an annual rate of $16 \%$, resulting in an average nominal power of $6.8 \mathrm{MW}$ in 2018 [20]. The world largest wind turbine is installed in the United Kingdom, with a nominal power of 8.8 MW [20]. Currently, however, wind turbines with a nominal power above $12 \mathrm{MW}$ are in development. ${ }^{1}$

Typical offshore wind farms consist of both a number of wind turbines (WT) and a manned offshore substation (OSS). The latter is usually located at the center of the wind farm and is used for maintenance. Transportation of maintenance engineers is performed by crew transfer vessels (CTV) or by rotorcraft. CTVs offer high passenger and cargo capacity, but they are typically limited up to sea state 4 [9] and passengers may be affected by seasickness. In contrast, rotorcraft benefit from short transfer time and their operation within offshore wind farms is in practice limited to sea state 6. Typical maritime helicopter operations are the transportation of maintenance engineers from mainland to the OSS or from the OSS to one single WT. However, there remain a number of issues regarding the operation of helicopters within wind farms. Aspects which have to date seen limited research activity include interaction with turbulent WT wakes and the impact of offshore weather conditions (degraded visual environment, precipitation). An overview of recent research activities in Europe is described in a report compiled by members of the GARTEUR Helicopter Action Group 23 (HC-AG23, [7]).

Currently, German regulations for safety clearances for operations in offshore wind farms are based upon estimates, defined by the geometry of WTs and empirical experience. The rotor radius of the WT is used as a scaling factor in calculations. However, the influence of wind speed, its direction and the WT wake is neglected. Interaction with blade

\footnotetext{
1 https://www.ge.com/renewableenergy/wind-energy/offshore-wind/ haliade-X-offshore-turbine, accessed 21 May 2019.
}

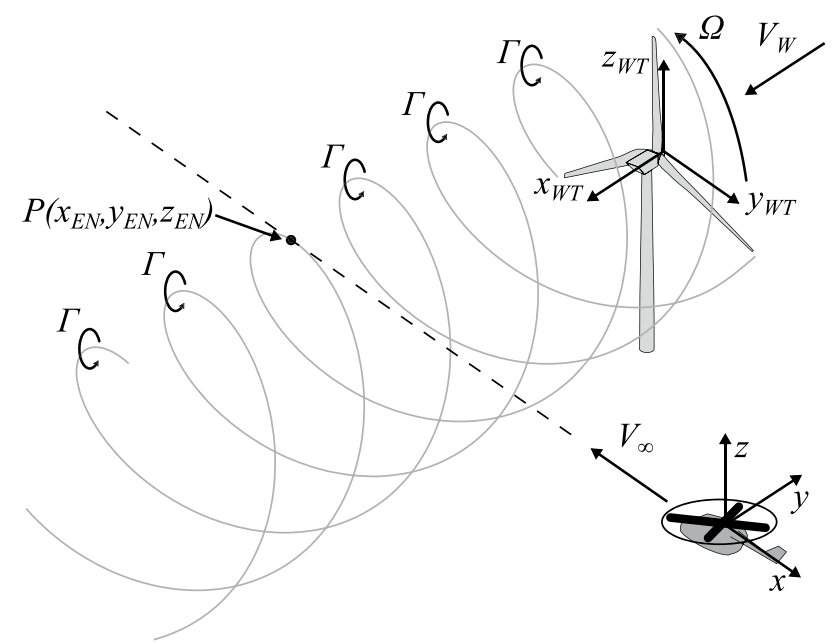

Fig. 1 Experimental setup of the piloted simulation

tip vortex from the WTs is a particular concern, continuing prior research regarding rotorcraft encountering fixed-wing aircraft vortex wakes [18].

To assess the suitability of current helicopter operations within offshore wind farms, the German Aerospace Center (DLR) is leading the project HeliOW (Helicopter Offshore Wind). This project is funded by Federal Ministry for Economic Affairs and Energy (BMWi) and is a collaborative research project between DLR, Technical University Munich, University of Stuttgart and University of Tübingen. The aim of the project is to investigate potential safety hazards which may result from operating in offshore wind farms and to define methods and practices for future operations.

Within the project, DLR is responsible for activities concerning pilot-in-the-loop simulations during flights in offshore wind farms. To investigate this, studies are being conducted within DLR's ground-based Air Vehicle Simulator (AVES). In this paper, the results from a study conducted in AVES to determine the severity of wake interactions within an offshore wind farm are presented. The visual environment consists of a typical wind farm, but only the wake of one single WT is modeled. As indicated in Fig. 1, the helicopter crosses the upper boundary of the WT wake and the severity of the wake encounter is rated by the pilots. Results of this study will be used to assess necessary safety clearance of flight corridors during forward flight. The requirements have been investigated both for WTs representing those currently in operation and WTs projected to be used in the future (larger, more powerful).

One approach taken in this research effort is to compare wake encounters with control system failures. Rotorcraft Handling Qualities (HQ) guidelines, Aeronautical Design Standard 33 (ADS-33E-PRF, [1]) contain requirements for the response of the aircraft following failures. The response 
Table 1 Requirements for helicopter motion transients following control system failures (ADS-33E-PRF, [1])

\begin{tabular}{|c|c|c|c|}
\hline \multirow[t]{3}{*}{ Level } & \multicolumn{3}{|l|}{ Flight condition } \\
\hline & \multirow{2}{*}{$\begin{array}{l}\text { Hover and low } \\
\text { Speed }\end{array}$} & \multicolumn{2}{|l|}{ Forward flight } \\
\hline & & Near earth & Up-and-away \\
\hline 1 & $\begin{array}{l}3^{\circ} \text { roll, pitch, yaw } \\
0.05 \mathrm{~g} \mathrm{nx}, \text { ny, nz } \\
\text { No recovery action for } 3 \mathrm{~s}\end{array}$ & $\begin{array}{l}\text { Both hover and low speed and forward flight } \\
\text { up-and-away requirements apply }\end{array}$ & $\begin{array}{l}\text { Stay within OFE } \\
\text { No recovery action for } 10 \mathrm{~s}\end{array}$ \\
\hline 2 & $\begin{array}{l}10^{\circ} \text { roll, pitch, yaw } \\
0.20 \mathrm{~g} \text { nx, ny, nz } \\
\text { No recovery action for } 3 \mathrm{~s}\end{array}$ & $\begin{array}{l}\text { Both hover and low speed and forward flight } \\
\text { up-and-away requirements apply }\end{array}$ & $\begin{array}{l}\text { Stay within OFE } \\
\text { No recovery action for } 5 \mathrm{~s}\end{array}$ \\
\hline 3 & $\begin{array}{l}24^{\circ} \text { roll, pitch, yaw } \\
0.40 \mathrm{~g} \text { nx, ny, nz } \\
\text { No recovery action for } 3 \mathrm{~s}\end{array}$ & $\begin{array}{l}\text { Both hover and low speed and forward flight } \\
\text { up-and-away requirements apply }\end{array}$ & $\begin{array}{l}\text { Stay within OFE } \\
\text { no recovery action for } 3 \mathrm{~s}\end{array}$ \\
\hline
\end{tabular}

is equivalent to the experience following a vortex wake encounter, where a quick change in the vehicle state occurs. Typically, the aircraft pitch, roll, and yaw attitude will be influenced by the presence of a local wind field. The sudden occurrence can be related to motion transients resulting from control system failures. This comparison has already previously been drawn in [18].

Table 1 shows the current classifications used to determine the predicted HQ level for rotorcraft following failures, both for hover and low speed and forward flight. Level 3 HQs would indicate deficiencies that require improvement (i.e. unacceptable characteristics). Level $2 \mathrm{HQs}$ indicate deficiencies that warrant improvement, which may be acceptable under certain conditions. The guidelines include the instruction no recovery action for 3,5 , and $10 \mathrm{~s}$. This is to reproduce the situation where the pilot does not recognize the failure or where his response is delayed due to divided attention. As an example, for Level 1 HQs following a failure, the vehicle attitude must change by less than $3^{\circ}$ without pilot intervention for $3 \mathrm{~s}$. These requirements are compared with the cases obtained in this investigation following vortex wake encounters from WTs.

The paper proceeds as follows. First, the current operations to offshore wind farms and regulations are discussed. Following, the modeling of the offshore environment and wind farms for real-time simulation is discussed, including information regarding scaling the WTs. Next, the piloted simulation study is presented, followed by the results of it. A discussion of these is presented along with conclusions and recommendations for future work.

\section{Offshore operations and wind turbine}

\subsection{Wind farm Global Tech I}

In this study, the offshore wind farm Global Tech I (GTI) is used for real-time simulation. This wind farm is located at the German North Sea coast and consists of 80 WTs, each with a nominal power of $5 \mathrm{MW}$. This particular wind farm was chosen due to its size and the location of the OSS, which is located in the center of the wind farm. This is to minimize working routes. Due to its position, it can only be reached by flying through a flight corridor, exemplary shown in Fig. 2. The size of this corridor is determined by the Federal Maritime and Hydrographic Agency of Germany (BSH) using current German regulations. It is split into an inner and an outer flight corridor. This wind farm is considered to be a good example of a current operational facility and presents good conditions to perform simulation campaigns.

The optimal sizing of the flight corridor for larger WTs in the future is important. Flight corridors being too wide would decrease the space utilization of wind farms and increase the cost of energy. However, if the corridors become too narrow, it may be a serious safety issue for helicopter operations and may cause problems reaching the platforms to perform the required maintenance.

During this investigation, the width of the flight corridor is taken as a constant parameter. Therefore, the flight corridor remains constant for WTs of different sizes, examining the potential need to increase the flight corridor for WTs up to $20 \mathrm{MW}$.

In general, the minimum flight altitude for visual flight rules (VFR) required by law outside of congested areas is $500 \mathrm{ft}(\approx 152 \mathrm{~m})$ above ground or water ([3], SERA.5005

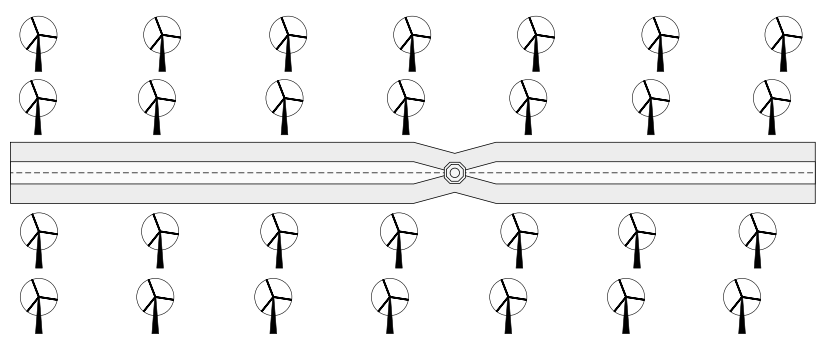

Fig. 2 Inner and outer flight corridor of Global Tech I (top view) 
f). For helicopter offshore operations at day time, the minimum flight altitude is reduced to $300 \mathrm{ft}(\approx 91 \mathrm{~m})$, unless the distance between offshore locations is less than $10 \mathrm{NM}$ and a flight underneath the cloud height is possible ([4], SPA.HOFO.130). This flight altitude corresponds to the hub height of the offshore WTs used in GTI.

Helicopter operations in offshore wind farms are limited by law to a wind speed of $60 \mathrm{kts}$ including gusts ([4], SPA. HOFO.135), which corresponds to sea state 8 (Table 9). However, in practice maritime helicopter operations are limited by different factors. Operational wind limits of typical helicopters used in offshore wind farms may be affect by the start/stop of the main rotor $(\approx 50$ to $55 \mathrm{kts}$, sea state 7, [6]) or by hoist operations ( $\approx 55$ to $90 \mathrm{kts}$, sea state $7-9$, [6]). In addition, those helicopters must equipped with a rotorcraft flotation system, which are typically certified up to sea state 6 [17]. In practice, helicopter operators have internal procedures, which limit for example hoist operations at offshore WTs to a wind speed of $35 \mathrm{kts}$ (sea state 6, Table 9).

From previous research efforts, it is known that helicopter vortex encounter is most critical during in-plane vortex interactions [21]. Therefore, the flight path in the piloted simulation is set to cross the upper boundary of one single WT wake within the wind farm (Fig. 1). In addition, the flight path is centered within the flight corridor (Fig. 2).

\subsection{Scaling of wind turbines}

The properties of the NREL $5 \mathrm{MW}$, an offshore WT widely used in research as a numerical reference, are taken here to represent the WT in the real-time simulation [14]. Its nominal power is identical to the WT used in the GTI. To assess the severity of future WTs, rules of similarity are used to upscale the reference WT to a nominal power of $12.5 \mathrm{MW}$ and $20 \mathrm{MW}$ [11]. The non-dimensional power and thrust coefficients are identical for all WTs. Consequently, the ratio of rotor blade tip speed $U$ to wind speed $V_{\mathrm{W}}$ remains constant.

The results of this scaling are shown in Table 2 and the rules of similarity are summarized in Eq. (1). Due to the scaling, the nominal power of the WT increases by the square of the rotor radius $R$. Furthermore, the rotational speed $\Omega$ decreases inversely proportional to the rotor radius $R$, which causes a widening of the stagger of the tip vortex helix.

$\frac{R_{2}}{R_{1}}=\frac{c_{2}}{c_{1}}=\frac{\Omega_{1}}{\Omega_{2}}=\sqrt{\frac{P_{2}}{P_{1}}}$.
Table 2 Rotor properties of the WTs

\begin{tabular}{llll}
\hline Parameter & $5 \mathrm{MW}$ & $12.5 \mathrm{MW}$ & $20 \mathrm{MW}$ \\
\hline$R, \mathrm{~m}$ & 63.0 & 99.6 & 126.0 \\
$f, 1 / \mathrm{min}$ & $6.9-12.1$ & $4.4-7.7$ & $3.5-6.1$ \\
$V_{\mathrm{W}, \Omega \min }, \mathrm{m} / \mathrm{s}$ & 3.0 & 3.0 & 3.0 \\
$V_{\mathrm{W}, \Omega \text { max }}, \mathrm{m} / \mathrm{s}$ & 11.4 & 11.4 & 11.4 \\
$\Omega, \mathrm{rad} / \mathrm{s}$ & $0.72-1.27$ & $0.46-0.80$ & $0.36-0.63$ \\
$U, \mathrm{~m} / \mathrm{s}$ & $45.5-79.8$ & $45.5-79.8$ & $45.5-79.8$ \\
$N_{\mathrm{b}}$ & 3 & 3 & 3 \\
$c(0.93 R), \mathrm{m}$ & 2.112 & 3.339 & 4.223 \\
$\Gamma_{0}, \mathrm{~m}^{2} / \mathrm{s}$ & 88.5 & 139.9 & 177.0 \\
$R_{\mathrm{c} 0}, \mathrm{~m}$ & 0.1056 & 0.1669 & 0.2112 \\
\hline
\end{tabular}

\section{Implementation of WT in AVES}

\subsection{Modeling of the WT wake}

The wake of the WT is modeled as a tip vortex helix as described in detail in [22]. Therefore, the shape of the tip vortex helix is prescribed and the expansion of the WT wake is neglected.

At first, the operating condition with the greatest tip vortex circulation $\Gamma_{0}$ is determined, which is the worst case scenario. Based on lifting line theory, the tip vortex circulation $\Gamma_{0}$ can be estimated using Eq. (2) [22]. The performance curves of [14] are used to determine the wind speed $V_{\mathrm{W}}$ with the maximum tip vortex circulation $\Gamma_{0}$. It is found at a wind speed of $V_{\mathrm{W}}=11.3 \mathrm{~m} / \mathrm{s}$, which is almost identical to the cut out wind speed $V_{\mathrm{W}, \Omega \max }$ of the WT (Table 2).

The initial vortex core radius $R_{\mathrm{c} 0}$ is defined as $5 \%$ of the reference chord of the blade at $93 \%$ radius (Eq. 3). Note that the radial position of the reference chord is chosen to take into account the geometry of tapered blade tips. The initial tip vortex circulation $\Gamma_{0}$ and the initial vortex core radius $R_{\mathrm{c} 0}$ for all WTs are listed in Table 2.

$\Gamma_{0}=\frac{\pi}{N_{\mathrm{b}}} \frac{V_{\mathrm{W}}^{2}}{\Omega} C_{\mathrm{T}, \mathrm{WT}}$,

$R_{\mathrm{c} 0}=0.05 c(0.93 R)$.

The operating condition of the WT with a wind speed of $V_{\mathrm{W}}=11.3 \mathrm{~m} / \mathrm{s}$ corresponds to a non-dimensional thrust coefficient of $C_{\mathrm{T}, \mathrm{WT}}=0.837$ in WT definition, which is equivalent to a non-dimensional thrust coefficient of $C_{\mathrm{T}}=0.0084$ in helicopter definition. A conversion between both nondimensional thrust coefficients can be performed with Eq. (4) $[22]$. 


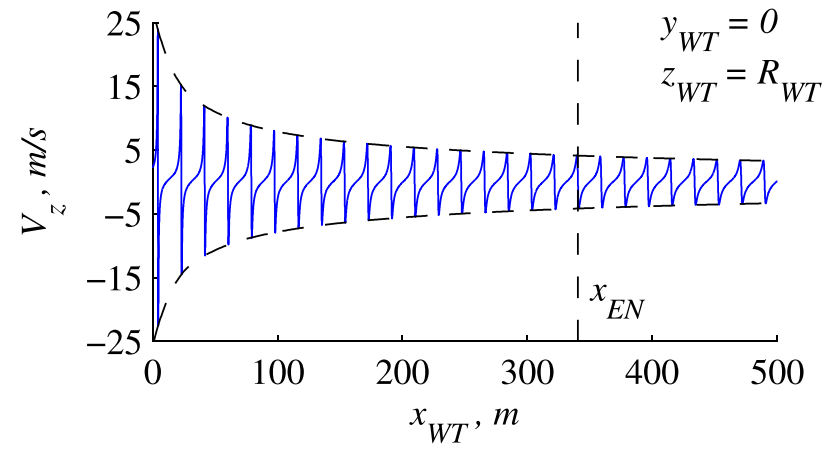

Fig. 3 Influence of vortex decay on vertical velocity of the 5 MW WT with $V_{\mathrm{W}}=11.3 \mathrm{~m} / \mathrm{s}$

$C_{\mathrm{T}}=\frac{1}{2}\left(\frac{V_{\mathrm{W}}}{U}\right)^{2} C_{\mathrm{T}, \mathrm{WT}}$.

Each revolution of the WT is discretized in 72 vortex line elements, which are described by the core radius model of Burnham-Hallock [8]. It describes the induced velocity $V_{\mathrm{i}}$ in dependence of the radial distance from the vortex core $\tilde{R}$, the vortex core radius $R_{\mathrm{c}}$ and the circulation strength $\Gamma$ (Eq. 5). Velocities are computed numerically, using the total induction of the line vortex elements of six revolutions of all WT blade tip vortices.

$V_{\mathrm{i}}=\frac{\Gamma}{2 \pi \tilde{R}} \frac{\tilde{R}^{2}}{\tilde{R}^{2}+R_{\mathrm{c}}^{2}}$.

The natural diffusion of each vortex element is modeled by an empirical time-dependent decay function for the vortex core radius $R_{\mathrm{c}}$ and the circulation strength $\Gamma$ as mentioned in [22]. During the convection downstream, it causes a widening of the vortex core $R_{\mathrm{c}}$ and a decrease of the circulation strength $\Gamma$ with time. Both correspond to a decrease of the peak-induced velocities.

Figure 3 depicts the vertical velocity $V_{\mathrm{z}}$ of the $5 \mathrm{MW}$ WT in the WT coordinate system (Fig. 1), extracted in a downstream cut at the upper height of the wake tube (Fig. 1), beginning at the WT, $x_{\mathrm{WT}}=0 \mathrm{~m}$. In addition, the envelope of peak vertical velocity profile is indicated with black dashed lines and the location of the vortex encounter $x_{\mathrm{EN}}$ is shown. It can be seen that the initial decay of the peak value of the vertical velocity $V_{\mathrm{z}}$ is rapid and then slows down at increasing distance. Note that due to the scaling method the peak vertical velocity profile is identical for the $12.5 \mathrm{MW}$ and the $20 \mathrm{MW}$ WT.

\subsection{WT wake characteristics}

The vortex core radius $R_{\mathrm{c}}$ and circulation $\Gamma$ at the vortex encounter depend on the state of decay and on the WT itself.

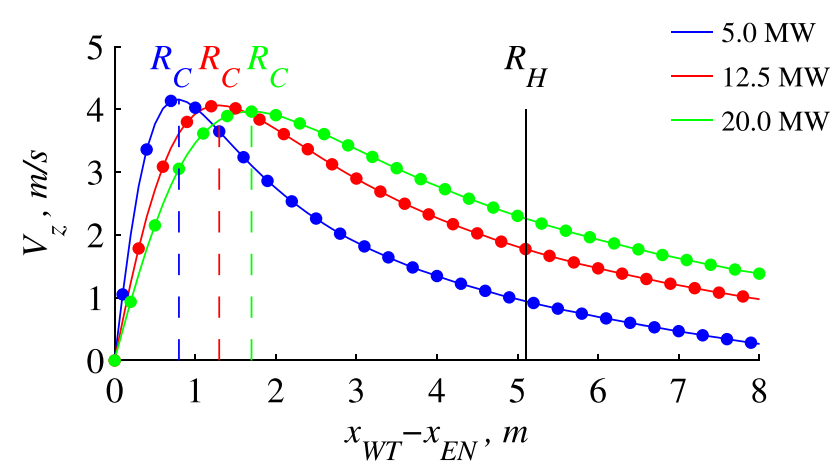

Fig. 4 Comparison of the vertical velocity profile $V_{\mathrm{z}}$ for different WTs

Figure 4 shows the vertical velocity profile $V_{\mathrm{z}}$ of a tip vortex from different WTs at the vortex encounter $x_{\mathrm{EN}}$. Note that $x_{\mathrm{EN}}$ is defined as the position of the vortex core center at the upper boundary (Fig. 1) for all WTs and its actual value depends on the WT size. The peak velocities are similar for all WTs, with the main difference being the vortex core radius $R_{\mathrm{c}}$. However, for all cases, the vortex core radius $R_{\mathrm{c}}$ remains small compared to the main rotor radius of the helicopter $R_{\mathrm{H}}$.

Note that the vertical velocity profile $V_{\mathrm{z}}$ is plotted with a high spatial resolution in Fig. 4. However, a spatial discretization of $\left(x_{\mathrm{WT}}=\Delta y_{\mathrm{WT}}=\Delta z_{\mathrm{WT}} \approx 0.3 \mathrm{~m}\right)$ is used for the piloted simulation and indicated with filled markers in Fig. 4. It can be seen, that spatial discretization is sufficient to cover the vertical velocity profile $V_{\mathrm{z}}$ at the vortex encounter $x_{\mathrm{EN}}$.

The geometry of the tip vortex helix is defined by the wind speed $V_{\mathrm{W}}$ and the WT radius $R$ and its rotational speed $\Omega$. Due to the different rotational speed $\Omega$ of the WTs, the distance between the tip vortices increases from $18.7 \mathrm{~m}(5$ MW WT) to $37.0 \mathrm{~m}$ (20 MW WT) as shown in Fig. 5.

The piloted flights were performed perpendicular to the WT wake tube as in Fig. 1 and the longitudinal axis of the helicopter is parallel to the $z_{\mathrm{WT}}$-axis in Fig. 5. Consequently, longitudinal axis of the helicopter is not perfectly parallel to the vortex axis at the upper boundary. The misalignment is estimated to be coarsely $8^{\circ}$ for all WTs (Fig. 5). In addition, the radius $R$ of the WT is finite and the tip vortex helix will behave similar to a straight line vortex only at the upper boundary. Both characteristics will cause slight deviations from an idealized longitudinal vortex interaction with simplified straight line vortices as used in [23].

Figure 6 shows a comparison of the three vortex-induced velocity components $\left(V_{x}, V_{y}, V_{z}\right)$ for virtual flights with a flight speed of $60 \mathrm{kts}$ behind the $20 \mathrm{MW}$ WT. For the ideal flight path (solid lines), the helicopter rotor hub remains exactly at the height of the WT wake tube and crosses the tip vortex core. In addition, a second case is shown with at height offset $\Delta H=1 \mathrm{~m}$ above the ideal case (dashed lines) 


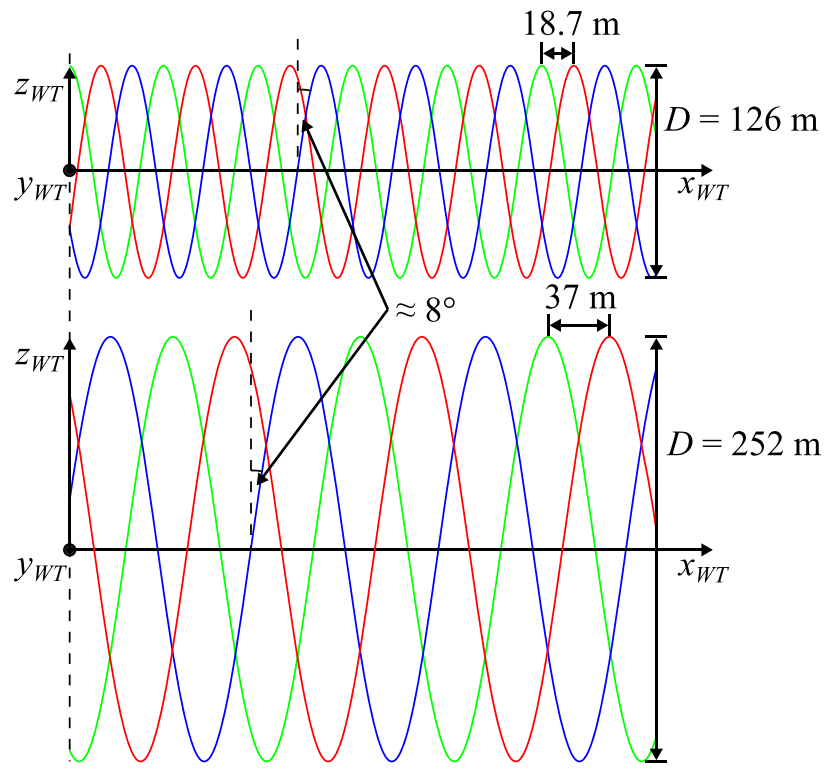

Fig. 5 Stagger of tip vortex helix of the 5 MW WT (top) and the 20 MW WT (bottom)

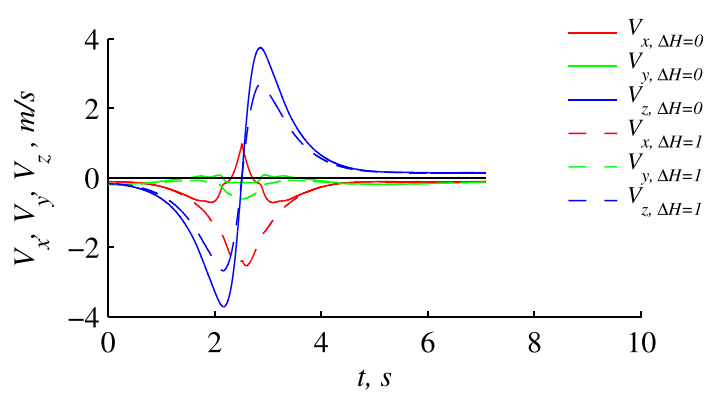

Fig. 6 Vortex-induced velocity components $\left(V_{x}, V_{y}, V_{z}\right)$ encountered during virtual flights with $60 \mathrm{kts}$ through a $20 \mathrm{MW}$ WT wake

and the tip vortex center is slightly missed, but the flight path is still experiencing the core radius of the vortex. This is why $V_{x}$ has a peak when passing over the vortex center. For longitudinal vortex interactions, the vertical velocity $V_{z}$ has a major influence on the helicopter behavior.

It can be seen in Fig. 6, that even small deviation from the ideal flight path causes reduction of coarsely $25 \%$ of the vertical velocity $V_{z}$. Therefore, care must be taken for the experimental setup to ensure the most critical helicopter reactions.

\subsection{Implementation of the helicopter/WT interaction}

The total wind speed $V_{\mathrm{W}, \mathrm{T}}$ within the piloted simulation and the helicopter flight speed $V_{\infty}$ are used to calculate the angle of attack and the Mach number at the aerodynamic elements of the helicopter model. Consequently, additional forces and moments are applied on each aerodynamic element. As indicated in Eq. (6), the total wind speed $V_{\mathrm{W}, \mathrm{T}}$ is divided into the global wind speed $V_{\mathrm{W}, \mathrm{G}}$ and the local wind speed $V_{\mathrm{W}, \mathrm{L}}$. The global wind speed $V_{\mathrm{W}, \mathrm{G}}$ is a constant parameter and has no spatial variations within the simulation environment. In contrast, the local wind speed $V_{\mathrm{W}, \mathrm{L}}$ describes local effects such as a wind deficit inside a WT wake. Therefore, it describes local deviations from the global wind speed $V_{\mathrm{W}, \mathrm{G}}$. For the first approach, the local wind speed $V_{\mathrm{W}, \mathrm{L}}$ varies only spatially and is fixed in time. Consequently, the tip vortex helix of the WT wake is fixed in space and does not convect downstream in this investigation. This is considered as a suitable approximation in this study, because the helicopter flight speed for most cases is larger than the vortex convection with the global wind speed of $V_{\mathrm{W}, \mathrm{G}}=11.3 \mathrm{~m} / \mathrm{s}$. However, for very low helicopter flight speeds, the impact of vortex convection may result in a longer vortex wake interaction, which may cause larger attitude changes of the helicopter.

$V_{\mathrm{W}, \mathrm{T}}(x, y, z)=V_{\mathrm{W}, \mathrm{G}}+V_{\mathrm{W}, \mathrm{L}}(x, y, z)$.

The magnitude of the global wind speed is set to $V_{\mathrm{W}, \mathrm{G}}=11.3$ $\mathrm{m} / \mathrm{s}$ to match the operating condition of the examined WTs with the maximum peak induced velocities and to obtain a worst case scenario. Precomputed velocity data of the WT wake model are used to describe the local wind speed $V_{\mathrm{W}, \mathrm{L}}$ of the real-time simulation. During simulation, they are used in form of a 3-dimensional lookup table, taking the position information from the helicopter model relative to the WT. Due to real-time constraints of the piloted simulation, a structured grid with equidistant spatial discretization is used to store the velocity data. The size of the WT wake domain is chosen as large as needed to have negligible velocities at its boundaries. In addition, an interpolation is performed at the boundaries to ensure a smooth transition into the WT wake domain.

A vehicle model of the ACT/FHS (Active Control Technology/Flying Helicopter Simulator, [15]) was selected for the investigation. The ACT/FHS is the experimental research helicopter maintained and operated by DLR. It is a highly modified version of an EC 135 series production helicopter. The vehicle features a fly-by-light full authority flight control system, an experimental computer system and an air data nose boom. As a result, the characteristics of the aircraft do not fully reflect those of the standard EC 135 helicopter. However, it is considered that the helicopter reactions of the ACT/FHS are representative of the class of rotorcraft expected to perform offshore operations such as the standard EC 135 helicopter. The properties of the ACT/FHS model are shown in Table 3.

DLR's non-linear helicopter modeling program, HeliWorX, was used to model the ACT/FHS. It is based on the real-time simulation model SIMH [12] and is used at the 
Table 3 Properties of the helicopter model used in the piloted simulation

\begin{tabular}{ll}
\hline Parameter & ACT/FHS \\
\hline$R_{\mathrm{H}}, \mathrm{m}$ & 5.1 \\
$f, 1 / \mathrm{min}$ & 395 \\
$\Omega, \mathrm{rad} / \mathrm{s}$ & 41.4 \\
$U, \mathrm{~m} / \mathrm{s}$ & 211 \\
$N_{\mathrm{b}}$ & 4 \\
Mass, $\mathrm{kg}$ & 2630 \\
\hline
\end{tabular}

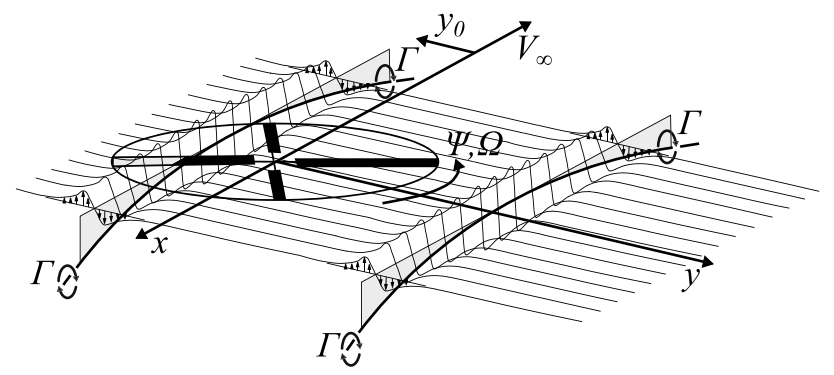

Fig. 7 Helicopter rotor in a curved WT wake from [22]

AVES center [10]. Helicopters are modeled as a rigid body with 6 degrees of freedom and are created using a set of modular components (fuselage, horizontal stabilizer, vertical stabilizer, main rotor, tail rotor, etc.). The main rotor is modeled as fully articulated with an equivalent hinge offset and spring restraint to represent the fundamental flapping and lagging natural frequencies. Each main rotor blade is modeled as a rigid blade and blade element theory is used to calculate the aerodynamic forces and moments. Overall ten blade sections are used to model each blade of the main rotor and the widely used dynamic inflow model of Pitt and Peters [19] is used for the piloted simulation.

The spatial discretization of the blade sections is finer at the blade tip than at the blade root. In addition, the temporal resolution of the main rotor is $1 \mathrm{~ms}$, which is equivalent to increments of $2.4^{\circ}$ of the rotor blade azimuth $\Psi_{\mathrm{B}}$. Therefore, the main blade tip moves a distance of $0.2 \mathrm{~m}$ per time step. Consequently, the smallest vortex core of the $5 \mathrm{MW}$ WT in Fig. 4 is resolved with coarsely 8 time steps by the blade tip, which is considered as sufficient for the real time simulation.

When flying within the WT wake, the local wind speed $V_{\mathrm{W}, \mathrm{L}}$ of the lookup table is interpolated on the reference points of each aerodynamic elements of the flight mechanic model. Therefore, the tip vortex helix of the WT wake has only a local effect as indicated in Fig. 7 at the retreating blade. Note that due to time constraints, the interaction between tail rotor and local wind speed $V_{\mathrm{W}, \mathrm{L}}$ has not been functional for this study, but will be in future work.
Table 4 Properties of the straight line vortex with its corresponding WT from [23]

\begin{tabular}{llll}
\hline Parameter & $x_{\mathrm{EN}}, \mathrm{m}$ & $V_{\mathrm{c}}, \mathrm{m} / \mathrm{s}$ & $R_{\mathrm{c}}, \mathrm{m}$ \\
\hline $7 \mathrm{MW}$ & 100 & 11.6 & 0.568 \\
\hline
\end{tabular}

The implementation of large aerodynamic elements such as the fuselage with only one reference point may lead to an overprediction of the additional forces and moments, because a single reference point is not representative for such large components. However, it is suitable for a conservative estimate of the helicopter reactions.

\subsection{Validation of interaction}

The validation of interaction is split into two parts, one focusing solely on the main rotor of the helicopter and one focusing on all aerodynamic elements.

At first, only the interaction between the ACT/FHS main rotor and the local wind speed $V_{\mathrm{W}, \mathrm{L}}$ is verified, using a modeled straight line vortex. This is compared to trim results of a Bo 105 main rotor at hover for longitudinal vortex interaction from [23]. For the validation of the main rotor response, the interaction with all other aerodynamic components is deactivated. Furthermore, the global wind speed $V_{\mathrm{W}, \mathrm{G}}$ is turned off to assess only the influence of the straight line vortex of the local wind speed $V_{\mathrm{W}, \mathrm{L}}$.

The same approach as in [23] is used. Therefore, the tip vortex helix is replaced by a straight line vortex, neglecting the curvature at the upper boundary of the helix (Fig. 7). For the comparison, the vortex core model of Lamb-Oseen is used (Eqs. 7-8).

$$
\begin{aligned}
& V_{\mathrm{i}}=\frac{\Gamma}{2 \pi \tilde{R}}\left(1-e^{-\beta_{v}\left(\frac{\tilde{R}}{R_{\mathrm{c}}}\right)^{2}}\right), \\
& V_{\mathrm{c}}=\frac{\Gamma}{2 \pi R_{\mathrm{c}}} .
\end{aligned}
$$

The vortex properties and results of the non-linear helicopter model HOST are provided by [23]. They correspond to a WT with a nominal power of $7 \mathrm{MW}$ in a distance of 100 m (Table 4).

For the validation, the helicopter is trimmed in hover condition with and without the straight line vortex. The former represents the baseline case and the latter is used to assess the influence of the straight line vortex. Its position relative to the rotor hub center $y_{0}$ is varied and is non-dimensionalized by the main rotor radius $R_{\mathrm{H}}$ (Fig. 7). This setup is also referred to as longitudinal vortex interaction. 


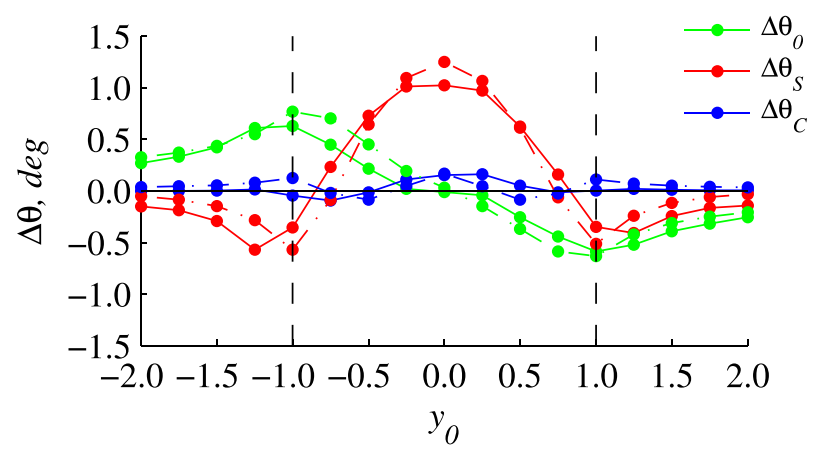

Fig. 8 Comparison of vortex impact on rotor control angles at hover for HeliWorX (solid line) and HOST (dash-dot line) from [23]

Figure 8 shows the change of the control angles $\left(\Delta \theta_{0}\right.$, $\Delta \theta_{\mathrm{S}}, \Delta \theta_{\mathrm{C}}$ ) compared to the baseline case for different vortex positions. The results of HeliWorX (solid line) are compared against the results of [23] (dash-dot line). As indicated by the vertical dashed lines, the vortex position $y_{0}$ is varied from far left to far right outside of main rotor. It is found that both simulations show the same trend, even though different helicopter rotors are used. The ACT/FHS has a bearingless rotor and the Bo 105 has a hingeless rotor. Both counterclockwise rotating rotors have in common, that flapping occurs due to the flexibility of the blade root and not by a mechanical flapping hinge. Nevertheless, the induced velocities of the vortex are nearly identical along the blade due to a similar main rotor radius. Therefore, a similar change of the control angles is sufficient to retrim the helicopter.

As stated in [21], the dynamic flapping response of hinged main rotors causes an excitation of both, the lateral and the longitudinal flapping angles $\left(\beta_{\mathrm{S}}, \beta_{\mathrm{C}}\right)$, depending on the hinge offset and its resulting phase delay. A centrally hinged rotor blade would have a response phase delay of exactly $90^{\circ}$, following the excitation. Due to the natural frequency of flapping of the EC 135 at 1.07/rev the fundamental blade flapping respond is with a phase delay of $78^{\circ}$.

For this interaction scenario, the vortex axis is almost perfectly in longitudinal direction of the rotor. Due to the sign of the vortex swirl rotation, the right half of the rotor is affected mainly by upstream and the left half is affected mainly by downstream. The maximum excitation will appear at the rotor blade azimuth $\Psi_{\mathrm{B}}=90^{\circ} / 270^{\circ}$, which is comparable with a change of the longitudinal control angles $\Delta \theta_{\mathrm{S}}$.

The result is an aerodynamic rolling moment with a very little aerodynamic pitching moment. Therefore, the dynamic rotor response is mainly a pitching moment and to a less extent a rolling moment, whose signs depend on the helicopter rotor sense of rotation.

The second part of validation concerns in addition the aerodynamic elements of the empennage (EMP), the fuselage (FUS) and the fin (FIN). In general, the implementation

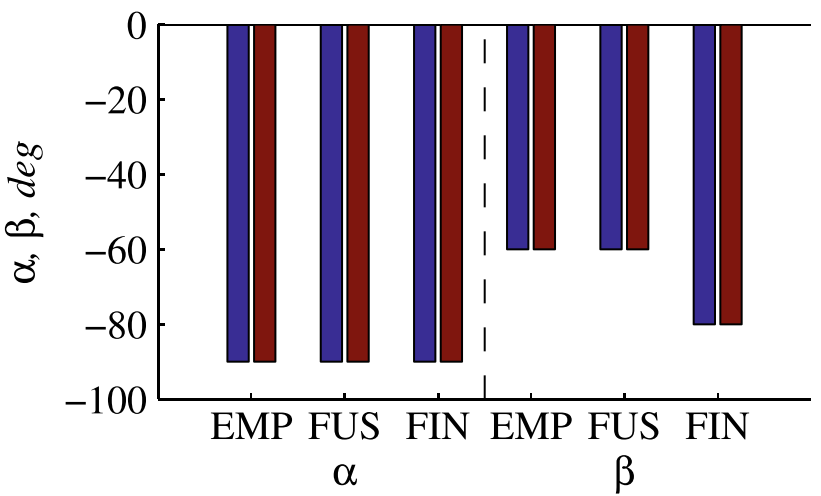

Fig. 9 Comparison of angles of attack $\alpha$ and sideslip $\beta$ for global (blue) and local wind model (red)

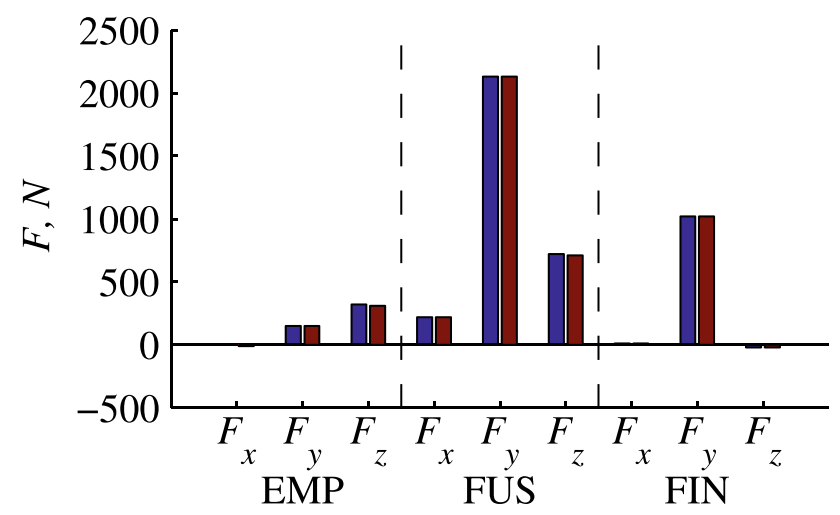

Fig. 10 Comparison of forces $F$ for global (blue) and local wind model (red)

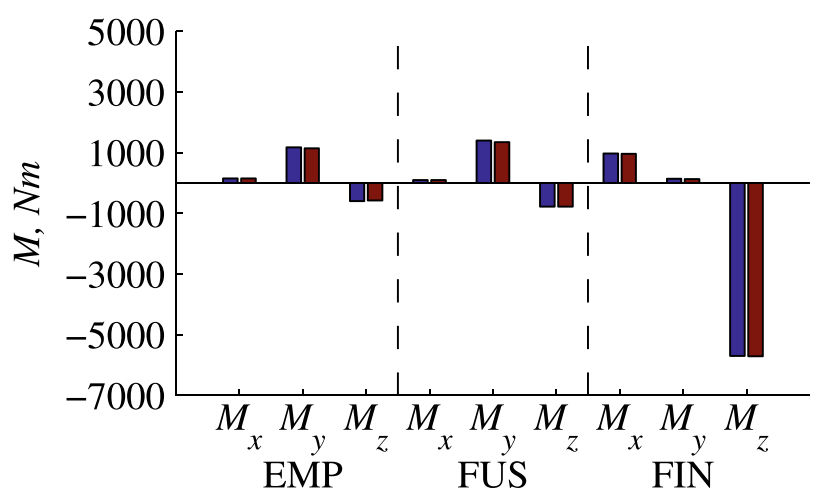

Fig. 11 Comparison of moment $M$ for global (blue) and local wind model (red)

between the flight mechanic model with the global wind speed $V_{\mathrm{W}, \mathrm{G}}$ is the same as with the local wind speed $V_{\mathrm{W}, \mathrm{L}}$. The only difference is the possibility to vary the wind speed locally. However, a homogenous wind lookup table for the local wind speed $V_{\mathrm{W}, \mathrm{L}}$ without any spatial variations has to produce the same results as the global wind speed $V_{\mathrm{W}, \mathrm{G}}$. 


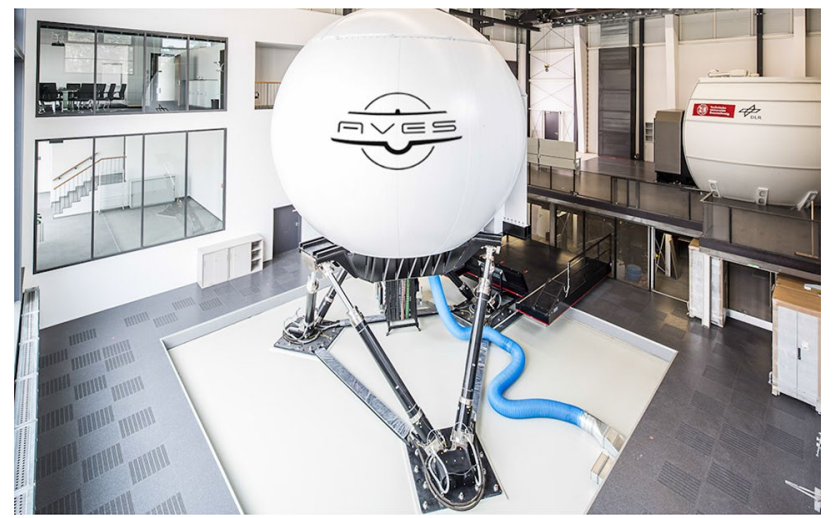

Fig. 12 AVES simulation facility

Consequently, the resulting angles of attack $\alpha$ and sideslip $\beta$, forces $F$ and moment $M$ should be identical for both wind models.

The global wind speed $V_{\mathrm{W}, \mathrm{G}}$ affects all aerodynamic elements of the flight mechanic model. As already mentioned, the interaction between the local wind speed $V_{\mathrm{W}, \mathrm{L}}$ and the tail rotor is not functional yet and, therefore, neglected for this wind model. As a consequence, the helicopter trim will slightly differ between both wind models in pitch, roll and yaw attitude, which results in deviations in the comparison.

Figures 9,10 and 11 show the comparison between trim results of global and local wind model for $20 \mathrm{kts}$ lateral wind at hover. This case is chosen, because the greatest influence of the missing tail rotor interaction with the local wind speed $V_{\mathrm{W}, \mathrm{L}}$ is expected. However, all aerodynamic elements show excellent agreement between both wind models. The same applies for headwind/upwind cases and are not shown here.

\section{Piloted simulation campaign}

\subsection{AVES facility}

The piloted simulation campaign was conducted in DLRs flight simulator AVES (Fig. 12). It is maintained and operated by the Institute of Flight Systems at DLR and features a replica of the ACT/FHS cockpit and the flight control system with experimental software. Experiments can be conducted with two pilots, a Flight Test Engineer (FTE) and a simulation operator. All experimental software is available when flying the simulator in the right-hand seat of the Evaluation Pilot (EP), as in the real aircraft. AVES also features dome visual projection and a full-size motion platform. The motion platform consists of a hexapod structure with six actuator legs to enable a limited six degrees of freedom motion. Each actuator leg has an operational range of $1.5 \mathrm{~m}$.

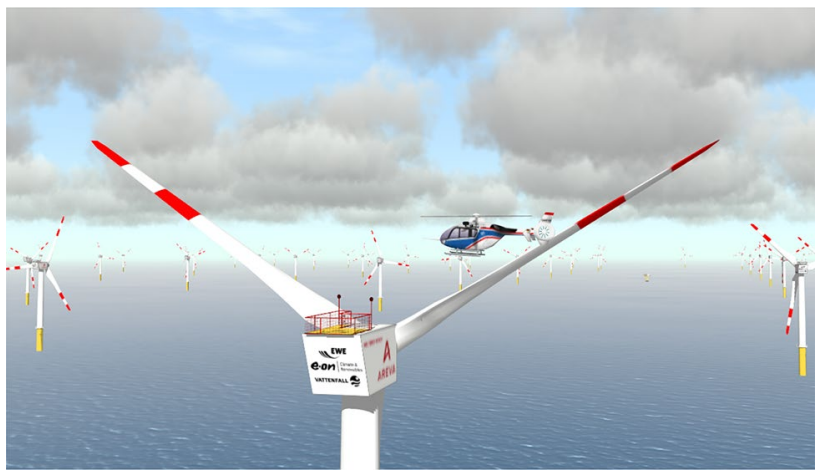

Fig. 13 Maritime offshore scenario of GTI

For this investigation, a dedicated visual environment was developed. This was to provide a realistic cueing environment to the pilot during the simulation campaign. The lack of available cues when flying offshore missions can be one factor that significantly contributes to the workload. This could lead to spatial disorientation. Therefore, it is important to complete the simulations using a realistic visual scenario, or a visual scenario that has been determined to be equivalent [16].

The visual scenario was built using the layout of the GTI. Figure 13 shows the external view of the helicopter approaching one of the WTs. Dynamic objects are included in the environment such as weather effects, dynamic waves and rotating WT blades.

\subsection{Experimental setup of piloted simulation}

The focus of this study is the assessment of the helicopter response due to vortex wake interactions generated by WTs of different sizes. In this investigation, it is important that the pilots are not distracted by upscaled very huge graphical WT models for each simulation run. A sizing of the WT in the visual environment of the simulation would give the pilots undesired hints about the strength of the WT wake and could influence the pilot reaction. Therefore, the graphical WT model was kept constant during this study. Consequently, the position of the wind lookup table of the local wind speed $V_{\mathrm{W}, \mathrm{L}}$ was shifted within the simulation to cause the vortex encounter at the same position.

Figure 14 shows the vertical shift of wind lookup table for the $5 \mathrm{MW}$ and the $20 \mathrm{MW}$ WTs. For the $5 \mathrm{MW}$ WT, the graphical WT model and wind lookup table match. Therefore, the tip vortex helix is placed concentric to the WT rotor hub (blue dashed circle). In contrast, the graphical WT model does not match to the $20 \mathrm{MW}$ WT, which is marked transparent in Figs. 14 and 15. The wind lookup table must be shifted downwards to cause the vortex encounter at the same altitude (green dashed circle). Consequently, the initial 


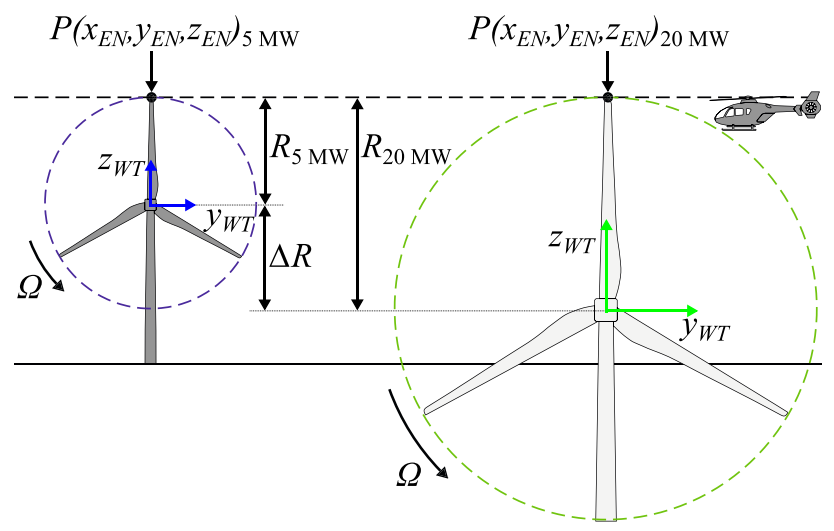

Fig. 14 Vertical shift of wind lookup table for $5 \mathrm{MW}$ (blue) and 20 MW (green)

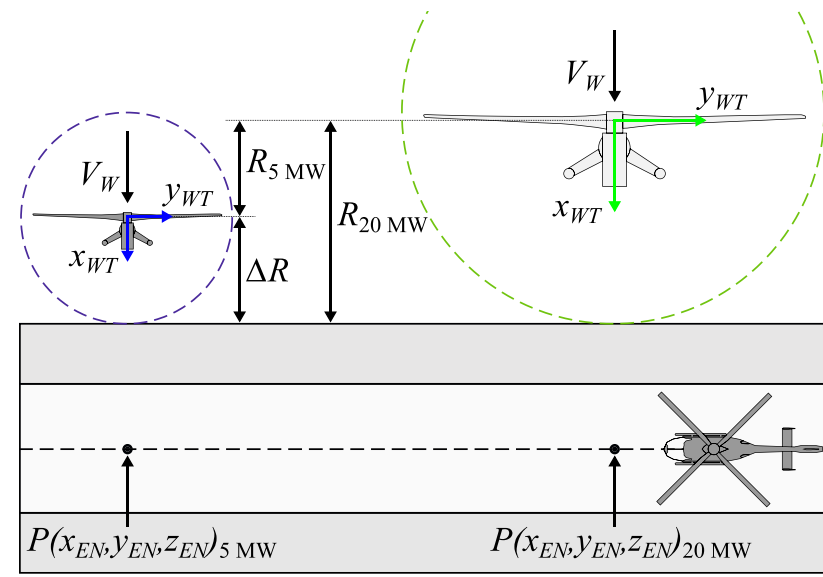

Fig. 15 Horizontal shift of wind lookup table for $5 \mathrm{MW}$ (blue) and 20 MW (green)

helicopter altitude remains the same for the piloted simulation for WT of different sizes and only the graphical model of the $5 \mathrm{MW}$ WT is visible.

Furthermore, the effect of the WT size on the distance to the vortex encounter has to be considered. For this study, the size of the flight corridor remains constant (Fig. 2), but larger WTs at exactly the same position would violate the outer flight corridor. Therefore, the wind lookup table is computed at the correct respective distance of encounter, but shifted horizontally within the simulation away from the flight corridor (Fig. 15). Consequently, the distance between helicopter and WT at the vortex encounter $x_{\mathrm{EN}}$ and therefore the vortex age differs slightly for the examined WT (Fig. 4). But the position of the helicopter within the flight corridor and the visual environment remains the same for all WTs.
Table 5 Pilot task performance requirements

\begin{tabular}{lll}
\hline Parameter & Desired & Adequate \\
\hline Speed, kts & $20,60,120 \pm 5$ & $20,60,120 \pm 10$ \\
Heading, ${ }^{\circ}$ & $270 \pm 5$ & $270 \pm 10$ \\
Altitude, $\mathrm{ft}$ & $510 \pm 10$ & $510 \pm 30$ \\
Recover time, $\mathrm{s}$ & 1.5 & 3.0 \\
\hline
\end{tabular}

\subsection{Task definition}

For the investigation, a mission task element was defined using the flight corridor of the GTI (Fig. 2). Figures 14 and 15 show a typical flight path identified as the situation where tip vortices could be encountered. This case is equivalent to the case shown in Fig. 1. For this study, it was important that the vehicle consistently encountered tip vortices. Therefore, for each simulation run, the aircraft was trimmed in proximity of the vortex encounter. The simulation ends, after the piloted has recovered the helicopter from the vortex encounter.

As shown in Fig. 6, small deviations from the ideal flight path cause a reduction of the local velocities and may cause weaker helicopter reactions. Therefore, the helicopter is trimmed at the initial position in close proximity of the vortex encounter to cross the wake tube at the upper boundary. The altitude of the helicopter rotor hub corresponds to the vertical position of the vortex encounter $z_{\mathrm{EN}}$ (Fig. 14). Furthermore, the helicopter is centered at the middle of the flight corridor and its longitudinal distance to the vortex encounter is coarsely $75 \mathrm{~m}$ (Fig. 15). As indicated in Fig. 6, this corresponds to a simulation time of about $2.4 \mathrm{~s}$ for a flight speed of $60 \mathrm{kts}$. Note that the initial helicopter position is within the wind lookup table, but its influence at the starting position at $t_{\mathrm{EN}}=0 \mathrm{~s}$ is negligible (Fig. 6).

The piloted simulation was executed at three different flight speeds: $20 \mathrm{kts}(10.3 \mathrm{~m} / \mathrm{s}), 60 \mathrm{kts}(30.9 \mathrm{~m} / \mathrm{s})$, and 120 $\mathrm{kts}(61.7 \mathrm{~m} / \mathrm{s})$ per run. In addition, at each flight speed the performance of the WT is also varied between $5 \mathrm{MW}, 12.5$ MW and $20 \mathrm{MW}$. The flight speeds are chosen because typically hovering is performed with a relative wind speed up to 20 kts. Furthermore, flights with helicopters to a helideck are limited to an absolute wind speed of $60 \mathrm{kts}$ and $120 \mathrm{kts}$ is a common cruising speed.

The pilot task is defined to recover the helicopter after the vortex encounter. The pilot is instructed to restore the flight speed, heading and altitude of the trim condition (as per tolerances in Table 5). If the helicopter is recovered within 1.5 $\mathrm{s}$ in the boundaries of the first column, the task is considered as desired. The same applies for the second column within 3 $s$ to achieve an adequate.

For typical maritime offshore operations, many current helicopters feature a stability augmentation system (SAS). 
To assess the most critical situation in this investigation, neither SAS nor any higher command control laws like attitude or translational rate command were used. Therefore, a bare-airframe model of ACT/FHS is used. Throughout the investigation, a global wind speed of $V_{\mathrm{W}, \mathrm{G}}=11.3 \mathrm{~m} / \mathrm{s}$ was used due to the chosen operating condition of the WT.

\subsection{Subjective assessment scales}

Currently there is no unified method to subjectively assess the severity of vortex encounter. In this study, two independent subjective assessment scales were used after each simulation run. These were the Upset Severity Rating (USR) and the Turbulent Air Scale (TS).

The USR has been presented in [18], a modified version of the transient control-system failure scale proposed in [13]. The scale is given in the Appendix (Fig. 25). It consists of a decision tree that allows the pilot to assess the combined helicopter behavior and possibility to recover following a disturbance. When using the scale, the pilot is required to begin in the bottom left corner. It is important that the pilot follows the structure to avoid erroneous ratings. The rating is categorized as either one of minor, major, hazardous, or catastrophic. The pilot is asked to determine if "recovery was possible" and "if the safety of flight was compromised".

To answer these questions, the pilot must have an understanding of the operational flight envelope of the vehicle. If the pilot states that recovery was not possible, he must award a rating of $\mathrm{H}$. This would be classed as catastrophic failure. ADS-33 defines that the probability of catastrophic failure must be less than $10^{-9}$ [1]. If the pilot believes that the safety was compromised, he must award either $\mathrm{F}$ or G, citing either major or hazardous encounter. These ratings are all determined as intolerable for vortex wake encounter. When the pilot determines that the safety was not compromised, a subjective rating between A and E should be awarded.

The corrective control action of the pilot can vary from "no action required" to an "immediate and extensive pilot effort is needed". A larger impact on the flight safety has the category major (rating F). In this category, a significant reduction of flight safety or an significant increase in crew workload is expected. The category hazardous (rating G) stands for a large reduction of the safety margin so that even with immediate critical control action and maximum pilot attention a safe recovery cannot be assured. If the impact of the encounter of a wake vortex is catastrophic (rating $\mathrm{H}$ ), the chance for the pilot to achieve a recovery is impossible.

The TS has been used as an additional measure to assess the impact of turbulence and is given in the Appendix (Table 8 ). The scale is a 10 point tabulated subjective assessment scale, taken from [2]. Similarly to the USR, the scale is divided into five levels; no, light, moderate, severe and extreme. Light turbulence (TS-2-TS-3) indicates smooth

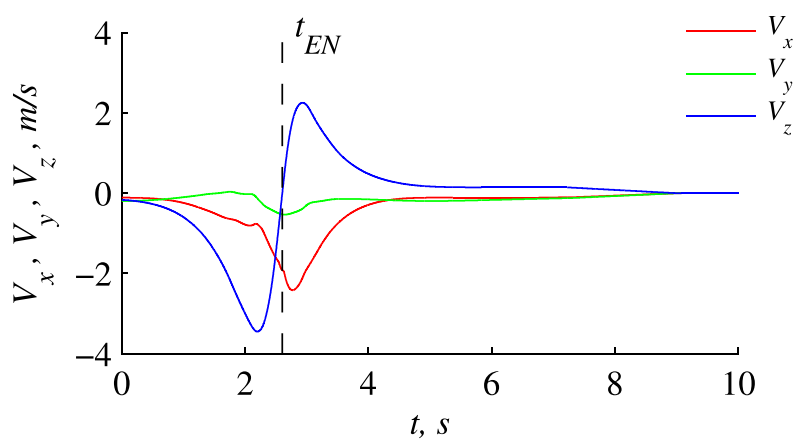

Fig. 16 Velocities of local wind speed $V_{\mathrm{W}, \mathrm{L}}$ at main rotor hub of RUN 19 (20 MW, $60 \mathrm{kts})$

and gentle movement, which may require limited corrections in manual control. Moderate turbulence (TS-4-TS-6) indicates "continuous small" or "medium bumps" or "occasional heavy bumps".

In the present investigation, turbulence encounters occurred only once during each simulation. For this reason, pilots were instructed to neglect the terms "continuous" and "occasional" and thus TS-6 has not been applicable in the investigation. When pilots felt they had experienced a "heavy bump", they were instructed to award TS-7. Severe turbulence (TS-8) includes cases where negative g occurred and extreme turbulence (TS-9-TS-10) is reserved for cases where the rotorcraft is difficult to control and/or the rotorcraft lifted several hundreds of feet. The TS scale does not include terms relating to loss of control or catastrophic failure, as in the USR scale.

The flight experience of pilots performing the task is given in the Appendix (Table 7).

\section{Results}

\subsection{Example of vortex encounter}

This section shows a typical example of the vehicle response following the $20 \mathrm{MW}$ WT wake encounter at a flight speed of $60 \mathrm{kts}$. The helicopter was starting trimmed and already located within the wind lookup table, with values of the local wind speed $\left(V_{\mathrm{W}, \mathrm{L}}\right)$ considered negligible at that position.

As shown in Fig. 16, the local wind speed at the rotor hub is non-zero around approximately $0 \mathrm{~s}$ (begin of flight simulation) and $10 \mathrm{~s}$ (end of simulation) with the largest influence between 1 and $5 \mathrm{~s}$ of the flight. The vortex core passage is indicated by the reversal of vertical wind speed at $t_{\mathrm{EN}}=2.6 \mathrm{~s}$. Due to the misalignment of the helicopter/ vortex longitudinal axis, the helicopter experiences first an upwind followed by a downwind after the vortex encounter. The peak velocity of the initial upwind is comparable to the 


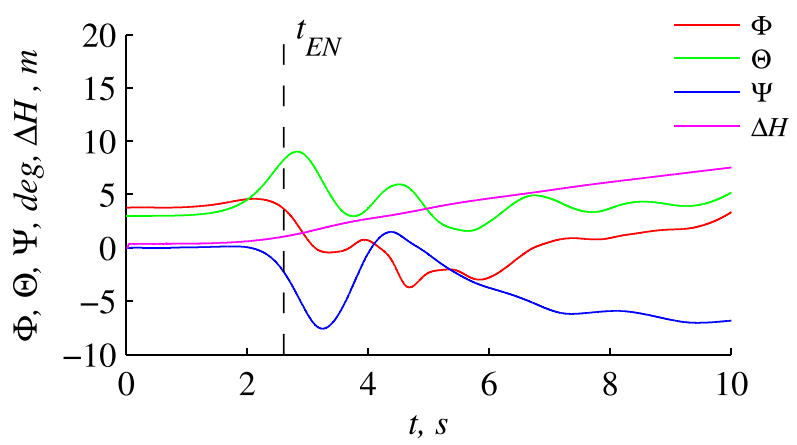

Fig. 17 Roll $\Phi$, pitch $\Theta$, yaw angle $\Psi$ and change of altitude $\Delta H$ of RUN 19 (20 MW, 60 kts)

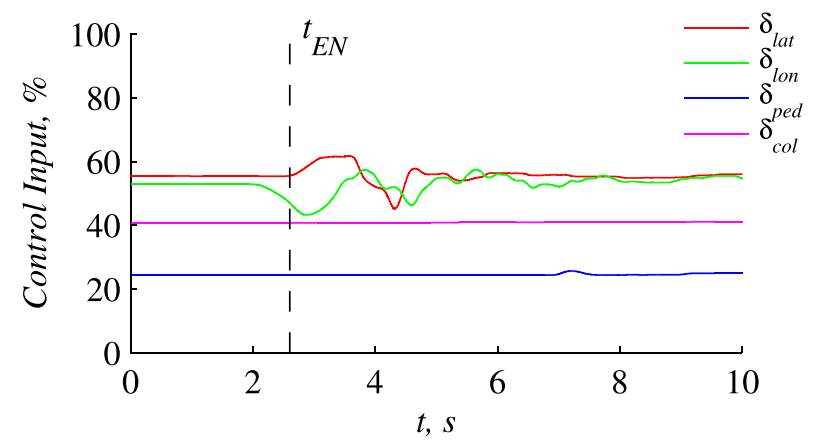

Fig. 18 Control input of RUN 19 (20 MW, 60 kts)

ideal flight path from Fig. 6. Therefore, the vortex core is considered to be crossed by the rotor hub.

Figure 17 shows the response of the vehicle for the roll $\Phi$, pitch $\Theta$, yaw angle $\Psi$ and the change of altitude $\Delta H$. Positive angles indicate roll right, pitch up and yaw right, respectively. Due to the initial upwind, the helicopter starts to pitch up and to climb. In addition, the helicopter experiences a very small roll right movement at the beginning, which quickly changes its directions before the vortex encounter. The yaw angle $\Psi$ decreases before the encounter. After the vortex encounter, the roll and pitch angles show a transient response to their initial values. The heading stabilizes, but a shift of $5^{\circ}$ remains compared to the initial condition. For this simulation run, a small climb rate remains unnoticed by the pilot.

Due to the experimental setup, the helicopter responses with a pitch up and climb reaction. This behavior is dependent on the rotor dynamics of the main rotor. An opposite sense of rotation of the helicopter main rotor or the WT rotor as well as an opposite flight direction may cause a pitch down and descent response.

Figure 18 shows the roll $\delta_{\text {lat }}$, pitch $\delta_{\text {lon }}$, yaw $\delta_{\text {ped }}$ and collective $\delta_{\mathrm{col}}$ command of the pilot during the simulation. Positive commands indicate positive roll, pitch, yaw and climb
Table 6 USR and TS pilot ratings

\begin{tabular}{|c|c|c|c|}
\hline \multirow[t]{2}{*}{ Speed } & \multicolumn{3}{|c|}{ Wind turbine power } \\
\hline & $5 \mathrm{MW}$ & $12.5 \mathrm{MW}$ & $20 \mathrm{MW}$ \\
\hline \multicolumn{4}{|l|}{ Pilot 1} \\
\hline \multirow[t]{2}{*}{$20, \mathrm{kts}$} & $\mathrm{B}, \mathrm{B}, \mathrm{B}$ & $\mathrm{B}, \mathrm{C}, \mathrm{C}$ & $\mathrm{C}, \mathrm{C}, \mathrm{C}$ \\
\hline & $3,3,3$ & $3,4,4$ & $5,5,4$ \\
\hline \multirow[t]{2}{*}{$60, \mathrm{kts}$} & $\mathrm{B}, \mathrm{C}, \mathrm{B}$ & $\mathrm{C}, \mathrm{C}, \mathrm{C}$ & $\mathrm{C}, \mathrm{C}, \mathrm{C}$ \\
\hline & $4,4,4$ & $4,4,4$ & $7,7,7$ \\
\hline \multirow[t]{2}{*}{$120, \mathrm{kts}$} & $\mathrm{B}, \mathrm{A}, \mathrm{A}$ & $\mathrm{C}, \mathrm{B}, \mathrm{B}$ & $\mathrm{B}, \mathrm{B}, \mathrm{B}$ \\
\hline & $4,3,3$ & $4,4,4$ & $4,4,4$ \\
\hline \multicolumn{4}{|l|}{ Pilot 2} \\
\hline \multirow[t]{2}{*}{20 , kts } & $\mathrm{C}, \mathrm{C}, \mathrm{C}$ & $\mathrm{C}, \mathrm{B}, \mathrm{C}$ & $\mathrm{B}, \mathrm{B}, \mathrm{B}$ \\
\hline & $7,5,4$ & $4,4,4$ & $3,4,4$ \\
\hline \multirow[t]{2}{*}{$60, \mathrm{kts}$} & $\mathrm{B}, \mathrm{B}, \mathrm{B}$ & $\mathrm{C}, \mathrm{C}, \mathrm{C}$ & C, C, B \\
\hline & $3,3,3$ & $4,4,4$ & $7,7,7$ \\
\hline \multirow[t]{2}{*}{$120, \mathrm{kts}$} & - & $\mathrm{B}, \mathrm{C}, \mathrm{C}$ & C, D, D \\
\hline & - & $4,4,4$ & $7,7,7$ \\
\hline \multicolumn{4}{|l|}{ Pilot 3} \\
\hline \multirow[t]{2}{*}{$20, \mathrm{kts}$} & $\mathrm{C}, \mathrm{C}, \mathrm{B}$ & $\mathrm{C}, \mathrm{D}, \mathrm{C}$ & C, C, B \\
\hline & $3,4,4$ & $4,5,4$ & $4,4,3$ \\
\hline \multirow[t]{2}{*}{$60, \mathrm{kts}$} & $\mathrm{D}, \mathrm{B}, \mathrm{B}$ & $\mathrm{C}, \mathrm{C}, \mathrm{B}$ & $\mathrm{B}, \mathrm{B}, \mathrm{C}$ \\
\hline & $4,3,3$ & $3,3,3$ & $3,3,4$ \\
\hline \multirow[t]{2}{*}{$120, \mathrm{kts}$} & $\mathrm{B}, \mathrm{B}, \mathrm{B}$ & $\mathrm{C}, \mathrm{D}, \mathrm{B}$ & $\mathrm{B}, \mathrm{C}, \mathrm{D}$ \\
\hline & $2,2,3$ & $3,4,2$ & $3,4,4$ \\
\hline
\end{tabular}

rate commands, respectively. The pilot only begins to apply control input after about $2 \mathrm{~s}$ of the flight. This coincides with the first noticeable reactions of the helicopter from Fig. 17 and is just the time before the helicopter crosses the center of the vortex. To stabilize the vehicle following the disturbance, the pilot applies only roll $\delta_{\text {lat }}$ and pitch command $\delta_{\text {lon }}$. This was typical for cases investigated in this research. For example, the pilot applied control inputs in pitch and roll approximately $\pm 10 \%$ relative to the trim setting. This shows that significant control margin remained throughout and supports the pilot subjective evaluation that the case was not dangerous and was controllable throughout.

Overall, the changes in angular attitudes of the vehicle due to the vortex interaction remained under $\pm 10^{\circ}$ (Fig. 17). The pilot was not required to control the yaw response, due to the weathercock stability of the helicopter (Fig. 18). The heading excursions were not significantly large enough to force the pilot to take corrective action. Despite this, assuming that the yaw attitude must be recaptured within $1.5 \mathrm{~s}$ to achieve the desired task performance, this has been successfully achieved (Table 5). As the flight continues, a small drift in the heading is observed but was likely unnoticed by the pilot. 


\subsection{Pilot subjective assessment}

All pilots awarded ratings using the USR and TS, which are shown in Table 6. Using the USR scale, only ratings between $\mathrm{A}$ and $\mathrm{D}$ were obtained. This indicates no significant problems were experienced following the vortex encounter. The experience of the pilots was found to have a significant impact on the results obtained. For the two experimental test pilots (Pilot 1 and Pilot 2), the corrective control inputs for flying behind the $5 \mathrm{MW}$ WT were accomplished with minimal to moderate urgency. Pilot 3 exerted moderately more effort to stabilize the vehicle following the vortexwake encounter. This was shown through the simulation data obtained, with regards to the vehicle state and the pilot input.

Generally, USRs awarded indicated that there was more pilot correction required following encounters from the 12.5 MW and 20 MW WTs. No clear correlation was found between USRs and the flight speed of the helicopter. The USR scale was found to be coarse and ratings alone did not contain significant information regarding the overall influence of the wake encounter. Therefore, further detailed feedback from the pilots was required following each of the simulation runs. Furthermore, the pilots commented that the USR scale could be improved by higher resolution with a finer classification.

Concerning the task, pilots gave the feedback that the requirements were removed from those expected during offshore operations. During real operations, pilots stated that they would not try and stabilize the helicopter instantaneously following the encounter. This is due to the lack of the requirement during the operation. In the case that the pilots do not react to the turbulence interaction, for the majority of cases, the helicopter would stabilize by itself. Pilots commented that when attempting to stabilize the aircraft, pilotinduced oscillations were occasionally encountered. These could be avoided if the temporal demand to respond to the situation were removed.

In contrast, the TS ratings showed that some cases were assessed as TS-7 severe turbulence (Table 6). The reason for TS-7 was due to the modifications to the terms used in the scale. No turbulence cases were considered as extreme (TS-9-TS-10).

Generally, ratings showed a trend that the turbulences increase severity with increasing performance of the WT power. One exception is Pilot 2 at 20 kts. Generally, the ratings of Pilot 3 (non-test pilot) do not reflect those obtained from the other pilots. This pilot suggested that he had particular problems assessing the situation, and, therefore, was generally unsure about the ratings that he awarded.

Combined ratings of all pilots with respect to WT power and forward flight speed are shown in Figs. 19 and 20. The minimum and maximum ratings are given by the error bars. The marker shows the mean value obtained. Strictly

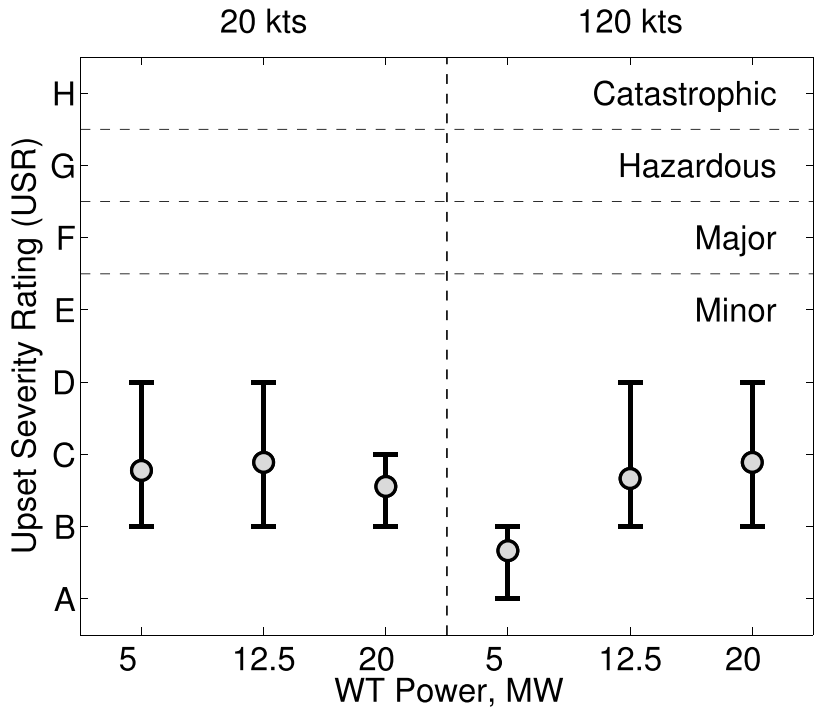

Fig. 19 Upset Severity Rating (USR) for all pilots with respect to WT power and forward flight speed

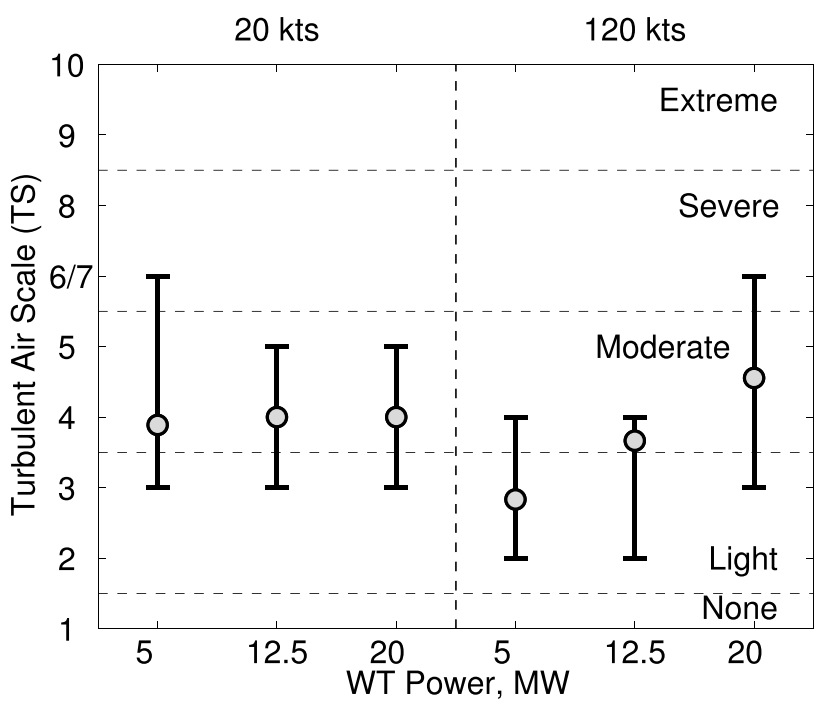

Fig. 20 Ratings awarded using the Turbulent Air Scale (TS) for all pilots with respect to WT power and forward flight speed

speaking, both the TS and USR are non-linear scales and the mean value does not take into account this non-linearities. With this in mind, the mean value is used only as an indication of the trend of results.

With regards to general severity of the turbulence encounters, using the USR scale suggests that no major problems were observed, which generally correlates with the feedback of the pilots. TS ratings show that occasional "severe turbulence" was experienced. In this respect, the severe turbulence has not caused safety of the flight to be compromised. The USR scale appears to be more suitable to determine the 


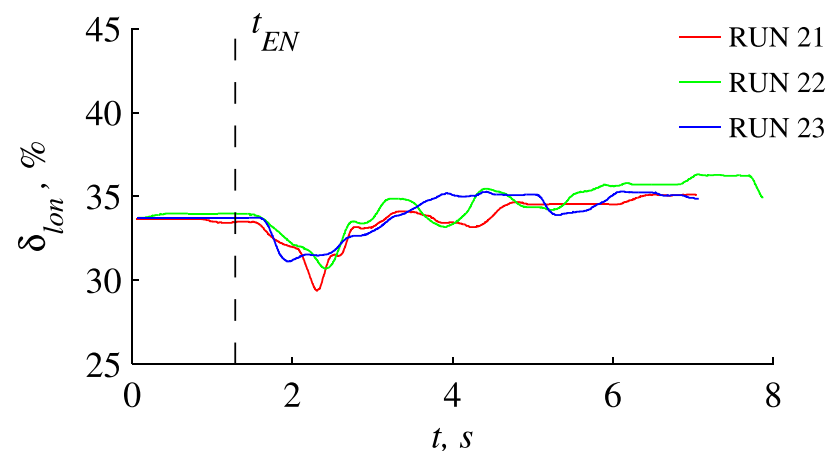

Fig. 21 Control input of Pilot 1 (20 MW, 120 kts)

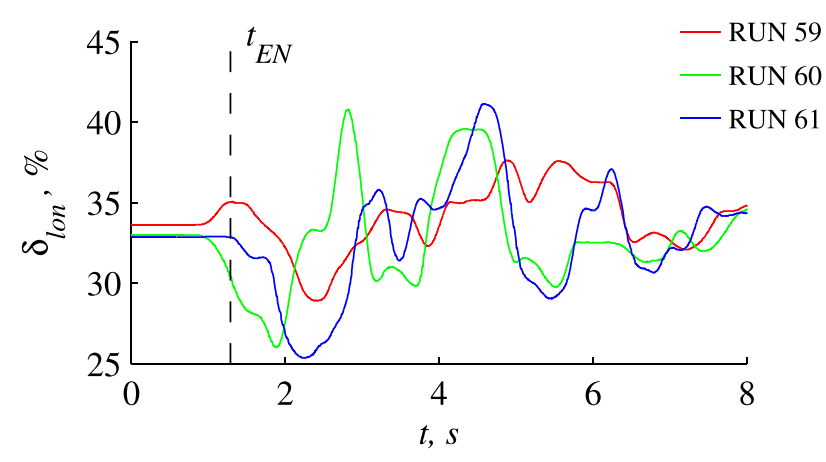

Fig. 22 Control input of Pilot 2 (20 MW, 120 kts)

severity of turbulence, and whether it significantly reduced the safety of flight. The modified TS scale is less suitable for this type of investigation due to the experimental setup. Therefore, the range of the modified TS rating is limited to a very coarse rating of "none", "light", "medium" and "heavy" single "bumps", which causes misleading results compared to the USRs.

\subsection{Pilot control strategy}

Disagreement between ratings obtained from pilots were found from the subjective measures, which can be explained by differences in the control strategies. Exemplary, a comparison between Pilot 1 and Pilot 2 is made. For both cases, the nominal power of the WT is $20 \mathrm{MW}$ and the selected flight speed is $120 \mathrm{kts}$.

According to the task performance requirements in Table 5, there are no explicit attitude limits (for pitch and roll), allowing to perform the task using different methods. As shown in Fig. 21, Pilot 1 used very low magnitude control inputs following the vortex interaction. For this reason, the pitch attitude change is corrected slowly, relying partly on the natural response of the aircraft (Fig. 23). In this way,

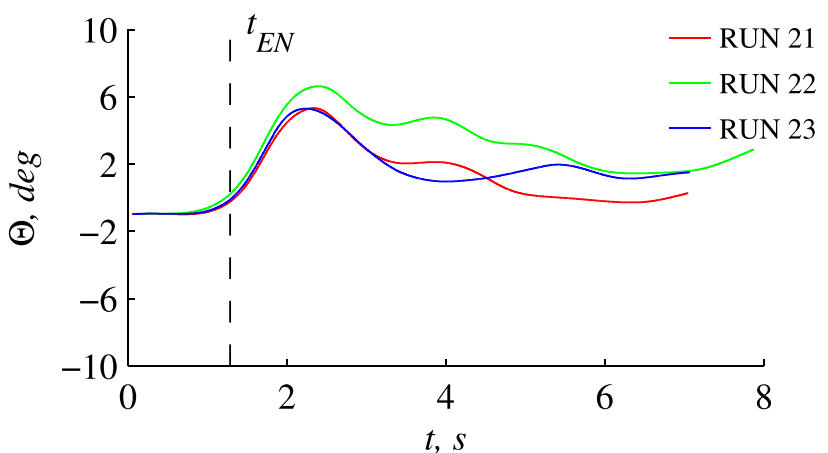

Fig. 23 Helicopter pitch attitude of Pilot 1 (20 MW, 120 kts)

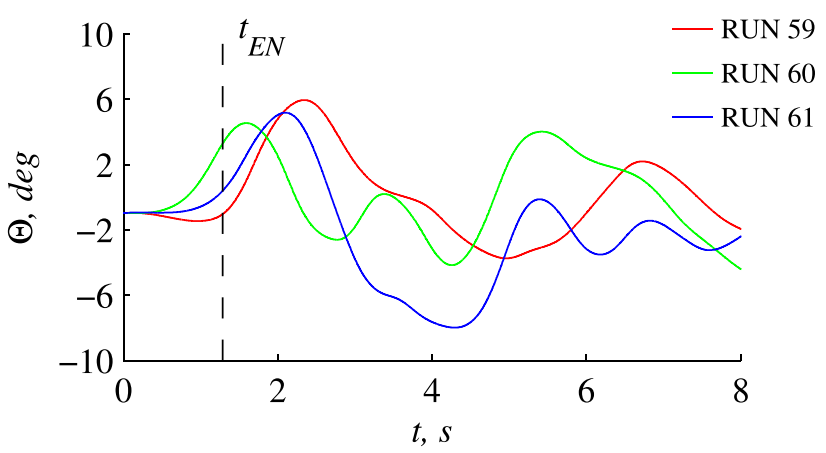

Fig. 24 Helicopter pitch attitude of Pilot 2 (20 MW, 120 kts)

the pilot applies an open-loop type command strategy during recovery to avoid oscillations.

In contrary, Pilot 2 attempted to stabilize the vehicle and arrest the following the disturbance. To arrest the pitch attitude, control inputs with much larger magnitude compared to Pilot 1 were applied (Fig. 22). Nevertheless, similar pitch attitudes were experienced by both pilots (Fig. 24).

Note that a time synchronization error occurred in the simulation data of Run 59, Run 60 and Run 61. Therefore, a time shift is visible in Figs. 23 and 24.

\section{Conclusion}

In this paper, a piloted simulation campaign determining the influence of vortex wake encounters in offshore wind farms on light utility helicopters with counter-clockwise rotating rotors has been presented and results have been discussed. The nominal power of the WT and the flight speed of the helicopter have been varied. A flight mechanic model of the research helicopter ACT/FHS, a highly modified EC 135, has been used. A semi-empirical wind turbine wake model has been used and the baseline WT was the NREL $5 \mathrm{MW}$, 
which has been scaled up to $12.5 \mathrm{MW}$ and $20 \mathrm{MW}$. A worst case scenario has been chosen with a WT operating with maximum tip vortex circulation. In addition, neither SAS nor any higher command control laws were used to control the helicopter. The following are the key conclusions from this effort:

- The results of the USR ratings range from $A$ to $D$, which represents the "minor hazardous" category. Modified TS ratings range up to TS-7, which is equivalent to "severe turbulence".

- The USR scale has been found to be more suitable compared to the TS rating for the assessment of the severity of the vortex wake interaction. It correlates better with the additional feedback of the pilots. Nevertheless, it has been stated that the resolution of the classification can be improved.

- The TS has been modified for this study by ignoring terms like "continuous" or "occasional" due to the single occurrence of the vortex encounter. Therefore, the range of the modified TS ratings is limited and the results may be misleading. As a result, pilots rated "severe turbulence" with TS and "minor hazardous" with USR at the same time.

- The upscaling of the WTs leads to very similar peak velocities at the vortex encounter. Mainly the vortex core radius differs, which is a side effect of the positioning of the wind table within the simulation.

- Overall, the piloted simulation with the semi-empirical wind turbine wake model suggests sufficient safety clearance within the wind farm even with very large WTs. However, the suitability of the WT wake model has to be compared against high fidelity models.

Future work will build on the simulation tools developed within in this simulation campaign:

- The missing interaction between the helicopter tail rotor and the local wind speed will be modeled and validated.

- The semi-empirical wind turbine wake model will be compared against high fidelity CFD data at the same operating condition to assess its accuracy.

- The interaction between helicopter and local wind speed will be extended for unsteady velocity data. Therefore, additional maritime helicopter operations can examined like hover behind a bluff body (e.g. halted WT).

\section{Appendix}

See Tables 7, 8, 9 and Fig. 25.

Table 7 Overview of pilot experience

\begin{tabular}{|c|c|c|c|}
\hline & Pilot 1 & Pilot 2 & Pilot 3 \\
\hline Pilot license & 42 years & 22 years & 11 years \\
\hline Experimental Test Pilot & Yes & Yes & No \\
\hline Aircraft experience & $\begin{array}{l}\text { EC 135, Bo 105, Bell 412, } \\
\text { Bell UH-1D, Alouette II }\end{array}$ & $\begin{array}{l}\text { Tomahawk PA38, Firefly } \\
\text { T67M260, Tucano T1, Hawk } \\
\text { T1/1A, AS350, B/AB 412EP, } \\
\text { Sea Kink Mk3/3A/4/5/7, } \\
\text { Chinook Mk 2/2A/3, A109E } \\
\text { Power, Gazelle AH1/HT3, } \\
\text { Lynx Mk7, S-92, Bo 105, EC } \\
135\end{array}$ & $\begin{array}{l}\text { Bo 105, EC 135, S-65, Bell } \\
\text { UH-1D, Cabri G2 }\end{array}$ \\
\hline Flight hours & $6500 \mathrm{~h}$ & $3600 \mathrm{~h}$ & $1100 \mathrm{~h}$ \\
\hline Offshore flights per year & 0 & 60 & 0 \\
\hline $\begin{array}{l}\text { Recent helicopter offshore experience } \\
\text { ( } \% \text { of flight hours) }\end{array}$ & $0 \%$ & $25-50 \%$ & $0 \%$ \\
\hline $\begin{array}{l}\text { Manoeuvre: } \\
\text { Landing OSS }\end{array}$ & 0 & more than 30 & 0 \\
\hline $\begin{array}{l}\text { Manoeuvre: } \\
\text { Hoisting with person }\end{array}$ & 0 & more than 30 & 0 \\
\hline $\begin{array}{l}\text { Manoeuvre: } \\
\text { Hoisting without person }\end{array}$ & 0 & more than 30 & 0 \\
\hline $\begin{array}{l}\text { Manoeuvre: } \\
\text { Ship deck landing }\end{array}$ & 0 & more than 30 & 0 \\
\hline
\end{tabular}


Table 8 Turbulent Air Scale (TS) with turbulence categories none (TS-1), light (TS-2-TS-3), moderate (TS-4-TS-6), severe (TS-7-TS-8) and extreme (TS-9-TS-10) from [2]

\begin{tabular}{lll}
\hline Scale & Definition & Air condition \\
\hline 1 & - & Flat calm \\
2 & Light & Fairly smooth, occasional gentle displacement \\
3 & Light & Small movements requiring correction if in manual control \\
4 & Moderate & Continuous small bumps \\
5 & Moderate & Continuous medium bumps \\
6 & Moderate & Medium bumps with occasional heavy ones \\
7 & Severe & Continuous heavy bumps \\
8 & Severe & Occasional negative "g" \\
9 & Extreme & Rotorcraft difficult to control \\
10 & Extreme & Rotorcraft lifted bodily several hundreds of feet \\
\hline
\end{tabular}

Table 9 Sea state code from World Meteorological Organization (WMO) from [5]

\begin{tabular}{lllll}
\hline Sea state code & Description of sea & Significant wave height & \multicolumn{2}{l}{ Wind speed } \\
\cline { 2 - 3 } & & $\mathrm{m}$ & $\mathrm{ft}$ & $\mathrm{k}$ \\
\hline 0 & Calm (Glassy) & 0 & 0 to $1 / 3$ & $0-3$ \\
1 & Calm (Rippled) & 0 to 0.1 & $1 / 3$ to $12 / 3$ & $4-6$ \\
2 & Smooth (Wavelets) & 0.1 to 0.5 & $12 / 3$ to 4 & $7-10$ \\
3 & Slight & 0.5 to 1.25 & 4 to 8 & $11-16$ \\
4 & Moderate & 1.25 to 2.5 & 8 to 13 & $17-21$ \\
5 & Rough & 2.5 to 4 & 13 to 20 & $22-27$ \\
6 & Very rough & 4 to 6 & 20 to 30 & $28-47$ \\
7 & High & 6 to 9 & 30 to 45 & $48-55$ \\
8 & Very High & 9 to 14 & Over 45 & $56-63$ \\
9 & Phenomenal & Over 14 & $64-118$ \\
\hline
\end{tabular}




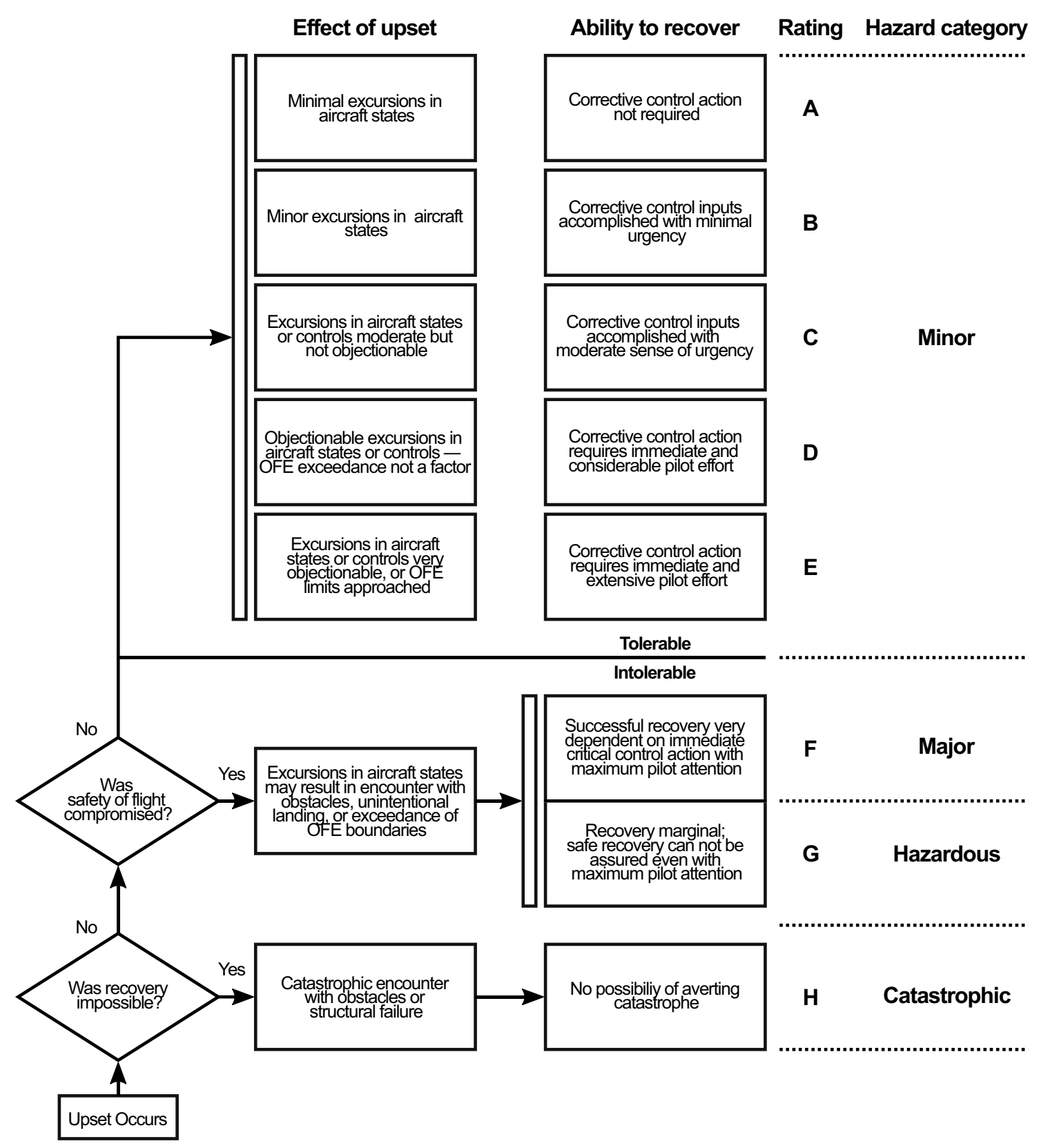

Fig. 25 Upset Severity Rating (USR) with hazard categories minor (A-E), major (F), hazardous (G) and catastrophic (H) from [18] 
Acknowledgements The piloted simulation was conducted at the AVES center within the framework of the national research project HeliOW (Helicopter Offshore Wind) funded by the German Federal Ministry of Economic Affairs and Energy (BMWi). The authors would like to thank everyone involved during the planning, preparation and execution of the simulator study.

\section{Supported by:}

\section{Federal Ministry for Economic Affairs and Energy}

\section{on the basis of a decision by the German Bundestag}

Funding Open Access funding enabled and organized by Projekt DEAL.

Open Access This article is licensed under a Creative Commons Attribution 4.0 International License, which permits use, sharing, adaptation, distribution and reproduction in any medium or format, as long as you give appropriate credit to the original author(s) and the source, provide a link to the Creative Commons licence, and indicate if changes were made. The images or other third party material in this article are included in the article's Creative Commons licence, unless indicated otherwise in a credit line to the material. If material is not included in the article's Creative Commons licence and your intended use is not permitted by statutory regulation or exceeds the permitted use, you will need to obtain permission directly from the copyright holder. To view a copy of this licence, visit http://creativecommons.org/licenses/by/4.0/.

\section{References}

1. Anon: Aeronautical Design Standard 33E PRF. Tech. Rep. ADS33E-PRF. United States Army Aviation and Missile Command (AMCOM), Redstone, AL (2000)

2. Anon: Defence Standard 00-970, Design and Airworthiness Requirements for Service Aircraft, Part 7-Rotorcraft. Tech. Rep. DEF STAN 00-970 Part 7/2-Section 9. Ministry of Defence, Glasgow, UK (2007)

3. Anon: European Union Commission Implementing Regulation (EU) No 923/2012 (2012)

4. Anon: European Union Commission Implementing Regulation (EU) No 965/2012 (2012)

5. Anon: Advisory Circular AC 29-2C-Certification of Transport Category Rotorcraft. Tech. Rep. AC 29-2C. U.S. Department of
Transportation (DOT), Federal Aviation Administration (FAA), Washington, D.C (2014)

6. Anon: Brochure Offshore Wind Energy. Airbus Helicopters (2018)

7. Bakker, R., Visingardi, A., van der Wall, B.G., Voutsinas, S., Basset, P.M., Campagnolo, F., Pavel, M., Barakos, G., White, M.: Wind Turbine Wakes and Helicopter Operations - An Overview of the Garteur HC-AG23 Activities. In: 44th European Rotorcraft Forum. Delft, Netherlands (2018)

8. Burnham, D.C., Hallock, J.N.: Chicago Monostatic Acoustic Vortex Sensing System-Volume IV: Wake Vortex Decay. Tech. Rep. DOT-TSC-FAA-79-18-4. U.S. Department of Transportation (DOT), Federal Aviation Administration (FAA), Washington, D.C (1982)

9. Dalgic, Y., Lazakis, I., Turan, O.: Investigation of optimum crew transfer vessel fleet for offshore wind farm maintenance operations. Wind Eng. 39(1), 31-52 (2015)

10. Duda, H., Gerlach, T., Advani, S., Potter, M.: Design of the DLR AVES research flight simulator. In: AIAA Modeling and Simulation Technologies (MST) Conference, Boston, MA (2013)

11. Gasch, R., Twele, J.: Windkraftanlagen-Grundlagen, Entwurf, Planung und Betrieb, 9th edn. Springer, Wiesbaden (2016)

12. Hamers, M., von Grünhagen, W.: Nonlinear helicopter model validation applied to realtime simulations. In: 53rd American Helicopter Society Annual Forum. Virginia Beach, VA (1997)

13. Hindson, W.S., Eshow, M.M., Schroeder, J.A.: A pilot rating scale for evaluating failure transients in electronic flight control systems. In: Atmospheric Flight Mechanics Conference. Portland, OR (1990)

14. Jonkman, J., Butterfield, S., Musial, W., Scott, G.: Definition of a 5 MW Reference Wind Turbine for Offshore System Development. Tech. Rep. NREL/TP-500-38060. National Renewable Energy Laboratory (NREL), Golden, CO (2009)

15. Kaletka, J., Kurscheid, H., Butter, U.: FHS, the New Research Helicopter: Ready for Service. In: 29th European Rotorcraft Forum. Friedrichshafen, Germany (2003)

16. Lehmann, P.H., Jones, M., Höfinger, M.: Impact of turbulence and degraded visual environment on pilot workload. CEAS Aeronaut. J. 8(3), 413-428 (2017)

17. Muller, M., Greenwood, R., Richards, M., Bark, L.: Survey and Analysis of Rotorcraft Flotation Systems. Tech. Rep. DOT/FAA/ AR-95/53. U.S. Department of Transportation (DOT), Federal Aviation Administration (FAA), Washington, D.C (1996)

18. Padfield, G.D., Manimala, B., Turner, G.P.: A severity analysis for rotorcraft encounters with vortex wakes. J. Am. Helicopter Soc. 49(4), 445-456 (2004)

19. Pitt, D.M., Peters, D.A.: Theoretical prediction of dynamic-inflow derivatives. Vertica 5, 21-34 (1981)

20. Selot, F., Fraile, D., Brindley, G.: Offshore Wind in Europe-Key Trends and Statistics 2018. Tech. Rep, WindEurope, Brussels, Belgium (2019)

21. van der Wall, B.G.: Rotor Thrust and Power Variations during InPlane and Orthogonal Vortex Interaction. In: 7th Asian/Australian Rotorcraft Forum. Seogwipo, Jeju Island, Korea (2018)

22. van der Wall, B.G., Fischenberg, D., Lehmann, P.H., van der Wall, L.B.: Impact of Wind Energy Rotor Wakes on Fixed-Wing Aircraft and Helicopters. In: 42nd European Rotorcraft Forum. Lille, France (2016)

23. van der Wall, B.G., Lehmann, P.H.: About the impact of wind turbine blade tip vortices on helicopter rotor. CEAS Aeronaut. J. 9(1), 67-84 (2018)

Publisher's note Springer Nature remains neutral with regard to jurisdictional claims in published maps and institutional affiliations. 